\title{
Pharmacological rescue of trafficking-impaired ATP-sensitive potassium channels
}

\author{
Gregory M. Martin, Pei-Chun Chen, Prasanna Devaraneni and Show-Ling Shyng*
}

Department of Biochemistry and Molecular Biology, Oregon Health \& Science University, Portland, OR, USA

\section{Edited by:}

Harley T. Kurata, University of British

Columbia, Canada

\section{Reviewed by:}

Mark Dunne, The University of Manchester, UK

Blanche Schwappach, University Medicine Göttingen, Germany Carol Vandenberg, University of California, Santa Barbara, USA

\section{*Correspondence:}

Show-Ling Shyng, Department of Biochemistry and Molecular Biology, Oregon Health \& Science University, L224, 3181 SW Sam Jackson Park Road, Portland, OR 97239, USA e-mail:shyngs@ohsu.edu
ATP-sensitive potassium ( $\mathrm{K}_{\text {ATP }}$ ) channels link cell metabolism to membrane excitability and are involved in a wide range of physiological processes including hormone secretion, control of vascular tone, and protection of cardiac and neuronal cells against ischemic injuries. In pancreatic $\beta$-cells, $K_{\text {ATP }}$ channels play a key role in glucose-stimulated insulin secretion, and gain or loss of channel function results in neonatal diabetes or congenital hyperinsulinism, respectively. The $\beta$-cell $K_{\text {ATP }}$ channel is formed by co-assembly of four Kir6.2 inwardly rectifying potassium channel subunits encoded by KCNJ11 and four sulfonylurea receptor 1 subunits encoded by $A B C C 8$. Many mutations in $A B C C 8$ or $K C N J 11$ cause loss of channel function, thus, congenital hyperinsulinism by hampering channel biogenesis and hence trafficking to the cell surface. The trafficking defects caused by a subset of these mutations can be corrected by sulfonylureas, K KTP channel antagonists that have long been used to treat type 2 diabetes. More recently, carbamazepine, an anticonvulsant that is thought to target primarily voltage-gated sodium channels has been shown to correct $\mathrm{K}_{\text {ATP }}$ channel trafficking defects. This article reviews studies to date aimed at understanding the mechanisms by which mutations impair channel biogenesis and trafficking and the mechanisms by which pharmacological ligands overcome channel trafficking defects. Insight into channel structure-function relationships and therapeutic implications from these studies are discussed.

Keywords: ATP-sensitive potassium channel, pharmacological chaperone, sulfonylurea, carbamazepine, congenital hyperinsulinism (CHI)

\section{INTRODUCTION}

ATP-sensitive potassium channels $\left(\mathrm{K}_{\mathrm{ATP}}\right)$ are a unique class of ion channels expressed in a variety of tissues including the pancreas, various regions of the brain, and cardiac, skeletal, and vascular smooth muscle (Aguilar-Bryan et al., 1998). By regulating $\mathrm{K}^{+}$ flux at the plasma membrane, they function as molecular sensors that couple cell metabolism to changes in membrane excitability (Nichols, 2006). The $\mathrm{K}_{\mathrm{ATP}}$ channel is a hetero-octamer formed by a complex of two distinct protein subunits in 1:1 stoichiometry: an inwardly rectifying $\mathrm{K}^{+}$channel Kir6.1/6.2 and a regulatory sulfonylurea receptor SUR1 or SUR2 (Inagaki et al., 1995, 1997; Clement et al., 1997; Shyng and Nichols, 1997). The "classic" channel subtype is composed of a tetramer Kir6.2, which forms the $\mathrm{K}^{+}$-conducting pore, with four surrounding SUR1 molecules, which provide regulatory functions.

In pancreatic $\beta$-cells, where $\mathrm{K}_{\mathrm{ATP}}$ channels are best studied, they act as a key link in glucose-induced insulin secretion (Aguilar-Bryan and Bryan, 1999; Ashcroft, 2005). In these cells, fluctuations in the $[\mathrm{ATP}] /[\mathrm{ADP}]$ ratio, brought about by changes in blood glucose levels, push the equilibrium of $\mathrm{K}_{\mathrm{ATP}}$ channels

Abbreviations: CBZ, carbamazepine; CF, cystic fibrosis; CFTR, cystic fibrosis transmembrane conductance regulator; $\mathrm{CHI}$, congenital hyperinsulinism; $\mathrm{K}_{\mathrm{ATP}}$, ATP-sensitive potassium channel; Kir6.2, inwardly rectifying potassium channel 6.2; NBD, nucleotide binding domain; PNDM, permanent neonatal diabetes; SU, sulfonylureas; SUR1, sulfonylurea receptor 1; TMD, transmembrane domain. toward the closed or open state. Thus, when blood glucose levels rise, the intracellular $[\mathrm{ATP}] /[\mathrm{ADP}]$ ratio also rises, blocking $\mathrm{K}^{+}$efflux through $\mathrm{K}_{\mathrm{ATP}}$ channels. This depolarizes the $\beta$-cell and opens voltage-gated $\mathrm{Ca}^{2+}$ channels; the subsequent $\mathrm{Ca}^{2+}$ influx then triggers exocytosis of insulin secretory granules. When blood glucose levels fall, the intracellular $[\mathrm{ATP}] /[\mathrm{ADP}]$ ratio will fall, pushing the equilibrium toward open $\mathrm{K}_{\mathrm{ATP}}$ channels, repolarizing the $\beta$-cell and blocking further insulin release (Figure 1).

Not surprisingly, mutations in the genes encoding $\mathrm{K}_{\mathrm{ATP}}$ channel subunits (ABCC8 for SUR1 and KCNJ11 for Kir6.2) often lead to a breakdown in glucose homeostasis. In general, mutations in $\mathrm{K}_{\mathrm{ATP}}$ genes are classified as either gain-of-function, where constitutively open channels preclude insulin secretion, or loss-of-function, non-functional channels that are unable to hyperpolarize the $\beta$-cell and cause persistent insulin release (Aguilar-Bryan and Bryan, 1999; Hattersley and Ashcroft, 2005). Over the past 15 years, a number of groups have identified a class of loss-of-function mutations in the genes encoding the $\mathrm{K}_{\text {ATP }}$ channel, particularly in $A B C C 8$ (SUR1), that interfere with proper biogenesis and trafficking, thus, preventing normal surface expression of the channel (Cartier et al., 2001; Partridge et al., 2001; Taschenberger et al., 2002; Crane and Aguilar-Bryan, 2004; Tornovsky et al., 2004; Yan et al., 2004, 2007; Taneja et al., 2009). These mutations are collectively referred to as trafficking mutations. Studies have demonstrated that congenital hyperinsulinism of infancy $(\mathrm{CHI})$, a rare disease characterized by persistent insulin 


\section{Resting state}

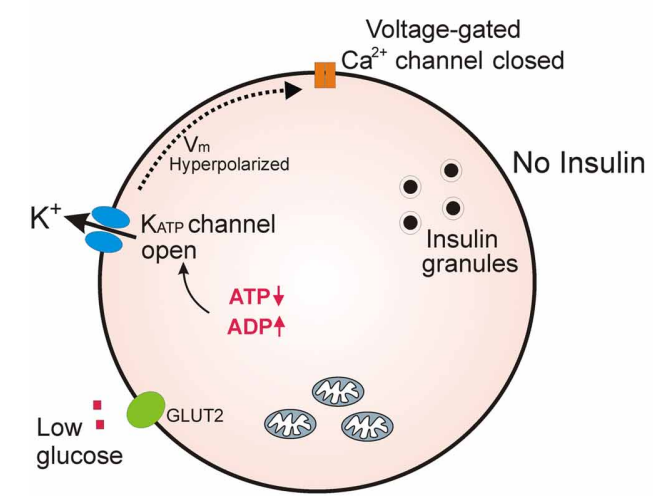

FIGURE 1 | $\mathrm{K}_{\text {ATP }}$ channels regulate insulin secretion in pancreatic $\boldsymbol{\beta}$-cells. Under conditions of low blood glucose, the relatively low ATP/ADP ratio in the $\beta$-cell promotes opening of $K_{\text {ATP }}$ channels, keeping $\beta$-cell membrane potential at a hyperpolarized state to prevent $\mathrm{Ca}^{2+}$ influx and insulin release. Upon an increase in blood glucose, $\beta$-cells increase glucose uptake through

\section{Glucose-stimulated state}

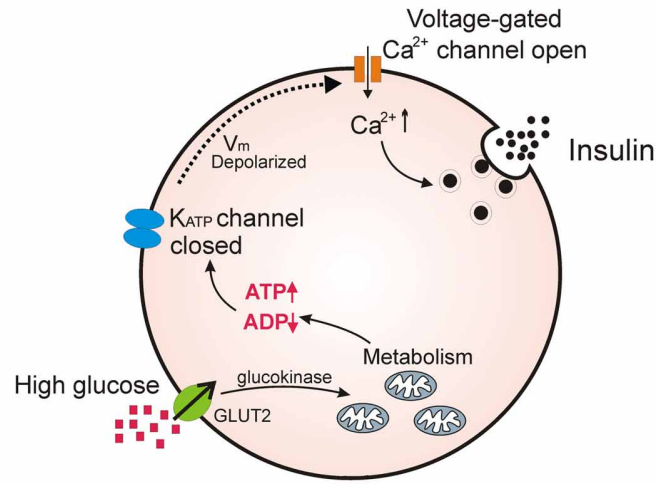

GLUT2 transporters; glycolysis and respiration then elevate the intracellular ATP/ADP ratio and close $K_{\text {ATP }}$ channels. This causes depolarization of the plasma membrane potential which opens voltage-gated $\mathrm{Ca}^{2+}$ channels; the subsequent influx of $\mathrm{Ca}^{2+}$ initiates fusion of insulin secretory granules with the plasma membrane. secretion even under severe hypoglycemia (Stanley, 1997), is frequently caused by trafficking mutations in $\mathrm{K}_{\mathrm{ATP}}$ channel genes. In these patients, channel subunits are synthesized but fail to reach the plasma membrane, mostly due to a disruption in the folding or oligomeric assembly process. The result is a constitutively depolarized $\beta$-cell with unregulated levels of insulin release. In many cases, the current therapy for these patients relies on partial or subtotal pancreatectomy to avoid permanent consequences of chronic hypoglycemia, which could lead to life-long insulin dependency.

Protein misfolding and mistrafficking resulting from genetic mutations underlie many human diseases. A prominent example is the $\triangle$ F508-CFTR (cystic fibrosis transmembrane conductance regulator) deletion mutation (Riordan et al., 1989), which is present in the majority of cystic fibrosis (CF) patients and causes defective folding, thereby inhibiting trafficking of the protein to the plasma membrane (Cheng et al., 1990). Small-molecule correctors, termed pharmacological chaperones, which specifically bind to a protein and enable its proper folding and localization, have been shown to correct trafficking defects in multiple diseasecausing proteins, like $\Delta$ F508-CFTR (Hanrahan et al., 2013). In some cases, mutant proteins rescued to the correct cellular locations exhibit full or partial function to reverse disease phenotypes (Powers et al., 2009). Recent work has demonstrated that pharmacological chaperones may also hold promise in correcting trafficking-impaired $\mathrm{K}_{\mathrm{ATP}}$ channels, offering new hope in the treatment of CHI.

In this review, we will discuss progress to date in defining the mechanisms by which mutations impair the biogenesis and trafficking of $\mathrm{K}_{\mathrm{ATP}}$ channels and how these trafficking defects can be overcome using pharmacological approaches. In particular, we will describe the challenges facing pharmacological rescue of trafficking-impaired ion channels, and discuss the promises this area holds in the treatment of disease.

\section{MOLECULAR COMPOSITION OF K $K_{\text {ATP }}$ CHANNELS}

The $\mathrm{K}_{\mathrm{ATP}}$ channel is a large hetero-octamer of nearly $950 \mathrm{kDa}$, composed of four Kir6.2 and four SUR1 subunits (Clement et al., 1997) (Figure 2). A low-resolution cryo-EM structure indicates a compact configuration, $18 \mathrm{~nm}$ across and $13 \mathrm{~nm}$ in height, with a central tetrameric Kir6.2 core which forms the $\mathrm{K}^{+}$-conducting pore, embraced by four SUR1 proteins (Mikhailov et al., 2005).

Kir6.2 is a member of the potassium inward rectifier family (Kir). These channels have a greater tendency to allow ion flow into, rather than out of the cell owing to block by intracellular polyamines and $\mathrm{Mg}^{2+}$ at positive membrane potentials (Lopatin et al., 1994). In the case of weak inward rectifiers such as Kir6.2, the extent of intracellular block is less pronounced due to lack of strong binding sites for the positively charged blockers. Under most physiological conditions where membrane potential is positive to the equilibrium potential of $\mathrm{K}^{+}\left(\mathrm{E}_{\mathrm{K}}\right)$, Kir channels generate small outward currents to keep membrane potential near the $\mathrm{E}_{\mathrm{K}}$. This makes Kir channels primary regulators of resting membrane potential in cells that express them. Importantly, many Kir channels are ligand-gated, endowing them the ability to couple specific physiological signals to membrane excitability (Nichols and Lopatin, 1997). For the Kir6.2-SUR1 K $\mathrm{ATP}_{\text {CP }}$ channel complex, gating regulation by intracellular nucleotides ATP and ADP underlies its physiological function of coupling cell metabolism to cell excitability.

No definitive high resolution structure for Kir6 channels yet exists. However, homology modeling using crystal structures of eukaryotic and prokaryotic Kir channels has provided the basis for a structural model (Capener et al., 2000; Loussouarn et al., 2001). Thus, four Kir6.2 subunits combine to form the $\mathrm{K}^{+}$pore. Each subunit has two transmembrane domains, M1 and M2, with intracellular N- and C-termini. Lying perpendicular to M1 and M2 is the short amphipathic "slide helix," which links M1 to the short N-terminal domain. Mutagenesis studies have implicated 


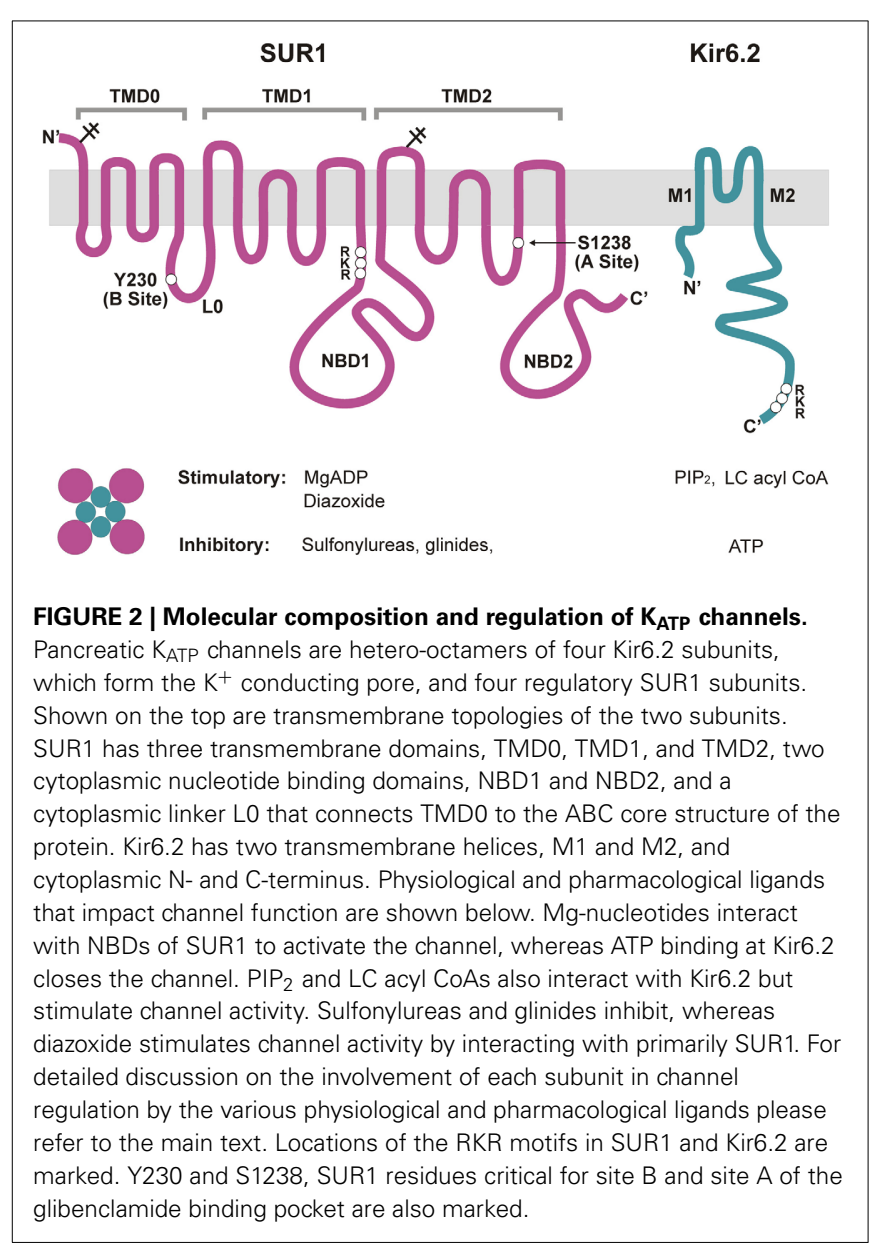

this region in channel gating (Proks et al., 2004; Lin et al., 2006b; Li et al., 2013). Interspersing M1 and M2 is an extracellular linker followed by a pore-forming loop, constituting the selectivity filter, the region responsible for $\mathrm{K}^{+}$ion specificity. The M2 helix connects to the large intracellular $\mathrm{C}$-domain. This region constitutes nearly half of the protein, and mediates extensive interactions with adjacent Kir6.2 subunits (Antcliff et al., 2005).

SUR1 is a member of the ATP Binding Cassette (ABC)-C family of transporters, and is closely related to CFTR and MRP (multi-drug resistance related proteins). Homology modeling has been challenging without a solved structure for an $A B C$ protein with significant sequence identity. Nonetheless, biochemical, electrophysiological, and mutagenesis studies have provided the essential topology and domain organization (Aguilar-Bryan et al., 1995; Tusnady et al., 1997; Conti et al., 2001) (Figure 2). As an ABC transporter, SUR1 has the core ABC structure of two transmembrane domains (TMD1 and TMD2), each consisting of 6 transmembrane helices. Each TMD is linked to a cytoplasmic nucleotide-binding domain (NBD1 and NBD2) by intracellular coupling domains (ICDs), $\alpha$-helical extensions of the TMDs. Additionally, SUR proteins contain an N-terminal TMD0 domain of five transmembrane helices, plus a long cytoplasmic loop L0, linking TMD0 with the core ABC structure. TMD0 is absent from most $\mathrm{ABC}$ transporters, including CFTR, and seems to play a unique and interesting role in $\mathrm{K}_{\mathrm{ATP}}$ channel biology. Studies implicate TMD0 in mediating interactions between SUR1 and Kir6.2 and modulating forward trafficking and gating of the channel (Schwappach et al., 2000; Babenko and Bryan, 2003; Chan et al., 2003). Another interesting point regarding SUR1 is the fact that this $\mathrm{ABC}-\mathrm{C}$ transporter has no known function as a transporter; its role is strictly regulatory with regard to Kir6.2, at least in the systems examined so far. How these two proteins evolved to form a functional channel complex is a fascinating question.

\section{BIOGENESIS AND TRAFFICKING REGULATION OF K $\mathrm{K}_{\text {ATP }}$ CHANNELS}

Biogenesis and assembly of $\mathrm{K}_{\mathrm{ATP}}$ channel proteins occurs in the ER (Zerangue et al., 1999). Not much is known regarding the events that couple translation of $\mathrm{K}_{\mathrm{ATP}}$ channel subunits to insertion in the ER membrane however, or regarding details of the assembly process and molecular chaperones involved. When either SUR1 or Kir6.2 is expressed alone in heterologous systems, the subunits cannot escape the ER (Zerangue et al., 1999) and are presumably cleared through ER-associated degradation (ERAD), suggesting that assembled complexes are required for forward trafficking and surface expression. Yan et al. confirmed that ubiquitin and proteasome-mediated ERAD is a primary check on $\mathrm{K}_{\mathrm{ATP}}$ channels during biogenesis and that this process in part regulates the surface expression of $\mathrm{K}_{\mathrm{ATP}}$ channels as inhibition of proteasome function led to an increase in surface expression of the channel (Yan et al., 2005). More recently, Wang and colleagues showed that Derlin-1, an ER membrane protein involved in recognition or retrotranslocation of substrates out of the ER for ERAD (Lilley and Ploegh, 2004; Ye et al., 2004), forms a complex with SUR1 and Kir6.2 and is also an important factor determining surface levels of $\mathrm{K}_{\mathrm{ATP}}$ channels (Wang et al., 2012). SUR1 is a glycoprotein, containing two N-linked glycosylation sites. Conti et al. mutated these sites in SUR1 and observed ER retention of the protein, suggesting that lectin chaperones calnexin/calreticulin, which are known to assist the folding of glycoproteins, participate in the folding and assembly of $\mathrm{K}_{\mathrm{ATP}}$ channels (Conti et al., 2002). Yan et al. also demonstrated that the molecular chaperone Hsp90 participates in the folding of $\mathrm{K}_{\mathrm{ATP}}$ channels by interacting with SUR1, and that knockdown of Hsp90 reduced surface expression of the channel (Yan et al., 2010). These studies only begin to address the sequence of events and the mechanisms that govern the folding/assembly and degradation of the $\mathrm{K}_{\mathrm{ATP}}$ channel, and represent important first steps in understanding this critical aspect of $\mathrm{K}_{\mathrm{ATP}}$ channel biology.

\section{ASSEMBLY DOMAINS}

A central question in understanding channel biogenesis is what are the assembly domains on the subunits themselves that direct this process? Using chimeras of Kir2.1, which is known to not associate with SUR1, and Kir6.2, Giblin et al. looked for minimal domains necessary for interactions between Kir6.2 and SUR1 (Giblin et al., 1999). They found that a proximal region (amino acids 208-279) in the Kir6.2 C-terminus is necessary for coimmunoprecipitation of the two subunits but this region is not sufficient to mediate formation of $\mathrm{K}_{\mathrm{ATP}}$ functional channel complexes as no channel activity could be detected at the cell surface. Schwappach et al., with a similar approach using chimeras of 
Kir6.2 and Kir2.1 demonstrated the M1 and N-terminus of Kir6.2 are involved in $\mathrm{K}_{\mathrm{ATP}}$ channel assembly and gating (Schwappach et al., 2000).

One particularly interesting assembly domain of the $\mathrm{K}_{\mathrm{ATP}}$ channel is TMD0, the first bundle of transmembrane helices in SUR1. This domain, coupled with the first intracellular loop L0, is largely unique to SUR proteins; most eukaryotic ABC transporters have only the core structure of TMD1 and TMD2 with the two intracellular nucleotide binding domains NBD1 and NBD2 (Tusnady et al., 1997). Using chimeric SUR1 proteins containing TMD0 from another ABC transporter MRP1 known to not interact with Kir6.2, Schwappach et al. first demonstrated a role of TMD0 in mediating subunit interactions between Kir6.2 and SUR1 and in promoting forward trafficking of Kir6.2 (Schwappach et al., 2000). Subsequent work by others showed that in truncated Kir6.2 subunits (see below), TMD0 alone will increase surface expression of Kir6.2 and produce so-called "mini-K $\mathrm{KTP}_{\mathrm{ATP}}$ channels that display single-channel kinetics similar to WT channels, but are unresponsive to metabolic signals and pharmacological ligands (Babenko and Bryan, 2003; Chan et al., 2003). Studies utilizing naturally occurring TMD0 mutations present in patients with $\mathrm{CHI}$ have identified residues which may be crucial for folding or subunit interactions (Chan et al., 2003; Yan et al., 2004, 2007; Pratt et al., 2011), but the precise nature of the interface of TMD0 with Kir6.2 remains to be elucidated.

\section{EXITING THE ER}

As mentioned, forward trafficking and surface expression of $K_{\text {ATP }}$ channels relies on assembly of both subunits in the ER. This makes Kir6.2 unique among Kir channels, thereby prompting studies to define the domain responsible for ER retention of unassembled Kir6.2 subunits. Tucker et al. first demonstrated that C-terminal truncations of 25 or 36 amino acids in Kir6.2 allowed for potassium currents in the absence of SUR1 (Tucker et al., 1997). Later work by Zerangue et al. utilized this seminal discovery in mapping the particular retention motif within the C-terminus of Kir6.2 and identified a tripeptide RKR localization signal (Zerangue et al., 1999) which was found to also function in SUR1 (Figure 2). The current model suggests these motifs must be masked during the assembly of the channel complex to allow forward trafficking to proceed. Unassembled or misassembled subunits are thus prevented from reaching the plasma membrane, allowing for quality control in the $\mathrm{K}_{\mathrm{ATP}}$ biogenesis pathway. Questions still remain regarding the mechanism of how the RKR motifs function in ER retention. A study by Yuan et al using an artificial reporter construct first brought forth a model whereby an interplay between the 14-3-3 family of proteins and the coatamer complex 1 (COPI) acts to regulate ER to Golgi trafficking via interactions with the RKR motifs (Yuan et al., 2003). Their group showed that COPI proteins can specifically bind the RKR motif in Kir6.2. The same study demonstrated 14-3-3 proteins can also recognize the signal when multiple subunits are present. The model proposes that COPI proteins recognize RKR motifs on misassembled or unassembled subunits and promote their retrieval to the ER. The 14-3-3 proteins, by contrast, act as sensors for assembled subunits, and can bind properly assembled complexes and prevent recognition of their RKR motifs by COPI, allowing forward trafficking to proceed. A later study from the same lab using the 14-3-3 scavenger approach further substantiated a role of 14-3-3 proteins in regulating trafficking and surface expression of heterologously and endogenously expressed $\mathrm{K}_{\mathrm{ATP}}$ channels (Heusser et al., 2006).

Anterograde, or forward trafficking signals on $\mathrm{K}_{\mathrm{ATP}}$ channel subunits have been more challenging to define. While TMD0 clearly facilitates Kir6.2 expression, it can only do so when co-expressed with Kir6.2 $\Delta$ C26, a C-terminal deletion construct missing the last 26 amino acids, in which the RKR motif resides (Chan et al., 2003). TMD0, therefore, is not the domain shielding the RKR signals from COPI proteins. Sharma et al. (1999) identified a putative forward trafficking signal in the distal Cterminus of SUR1 by making SUR1 constructs missing varying numbers of residues in the C-terminus (Sharma et al., 1999). However, another study showed that larger deletions in the SUR1 C-terminus had no effect on channel expression, making the existence of the C-terminal forward trafficking signal debatable (Giblin et al., 2002). No studies to date have resolved this issue or confirmed the existence of a bona fide anterograde signal on either subunit.

Interestingly, studies examining the kinetics of the biogenesis pathway using metabolic pulse-chase labeling have demonstrated the intrinsic inefficiency of $\mathrm{K}_{\mathrm{ATP}}$ assembly, estimating that only about $20 \%$ of newly synthesized SUR1 or Kir6.2 actually forms mature complexes, with the remaining pool being rapidly degraded (Yan et al., 2004, 2005, 2010; Chen et al., 2011). CFTR and other $\mathrm{ABC}$ transporters also display a similar level of efficiency (Ward and Kopito, 1994). Yan et al. have shown that both SUR1 and Kir6.2 exhibit a biphasic degradation profile when expressed alone, each containing a fast and a slow component (Yan et al., 2004, 2005). Crane and Aguilar-Bryan also observed biphasic degradation of Kir6.2 expressed alone; however, they reported remarkable stability of SUR1 expressed alone $(\sim 25 \mathrm{~h})$ (Crane and Aguilar-Bryan, 2004). These differences may be due to technical reasons or experimental conditions. Nevertheless, both groups saw increased stability of SUR1 and Kir6.2 when the two subunits were co-expressed, suggesting the subunits become more stable upon mulitimeric assembly (Crane and AguilarBryan, 2004; Yan et al., 2005). While some differences are yet to be resolved, studies like these address fundamental aspects of $\mathrm{K}_{\mathrm{ATP}}$ channel biology not by looking at snapshots, but by getting the dynamics involved in the biogenesis pathway. Many questions remain unanswered: How are nascent polypeptides recognized in the cytosol and translocated in the ER? What is the sequence of events involving folding and assembly of $\mathrm{K}_{\mathrm{ATP}}$ channel subunits? Is folding co- or post-translational? What protein-protein interactions occur in the ER that guide this process, and what molecular chaperones are involved? What routes do $\mathrm{K}_{\mathrm{ATP}}$ channels take after exiting the ER? Obviously much work needs to be done, but answers to these questions will provide a deep level of insight into how large, multimeric membrane proteins are assembled, and importantly, will allow researchers to more fully understand mechanisms of proteostasis and trafficking diseases, like $\mathrm{CHI}$ or CF. 


\section{GATING REGULATION OF K $\mathrm{K}_{\text {ATP }}$ CHANNELS}

It is well-understood that the primary mode of physiological regulation of $\mathrm{K}_{\mathrm{ATP}}$ channel function is through the opposing inhibitory action of ATP and stimulatory action of MgADP. The bulk ATP concentration is relatively stable in most cells, however, raising doubt that ATP can serve as a primary regulator of the channel. In $\beta$-cells, ATP concentrations have been estimated to change from 2 to $4 \mathrm{mM}$ when glucose is elevated from 0 to $10 \mathrm{mM}$ (Detimary et al., 1998); such high levels of ATP are expected to prevent channel opening even at the lowest glucose concentrations. However, the small changes in [ATP], coupled with much larger changes in ADP levels in the opposite direction as glucose concentrations fluctuate, result in significant changes in the $[\mathrm{ATP}] /[\mathrm{ADP}]$ ratio (Nilsson et al., 1996; Detimary et al., 1998) to shift the apparent ATP sensitivity and effectively regulate channel activity (Tarasov et al., 2004). Thus, when glucose levels are low, MgADP stimulation will predominate, $\mathrm{K}_{\mathrm{ATP}}$ channels will be open, the cell will be hyperpolarized, and no insulin will be secreted. When glucose levels are high, ATP inhibition will take over, closing $\mathrm{K}_{\mathrm{ATP}}$ channels, causing membrane depolarization, opening voltage-gated $\mathrm{Ca}^{2+}$ channels and triggering insulin exocytosis.

In the absence of ATP, $\mathrm{K}_{\mathrm{ATP}}$ channels display so-called burst kinetics, characterized by periods of rapid openings and closings separated by long closed intervals (Alekseev et al., 1997). ATP inhibition of $\mathrm{K}_{\mathrm{ATP}}$ channels, involving non-hydrolytic binding at the intracellular face of Kir6.2, acts to decrease the frequency and length of the burst periods, and increases the duration of the closed intervals (Babenko et al., 1999). Based on mutagenesis and docking studies using homology models of Kir6.2, binding is thought to occur at an interface involving the $\mathrm{N}$ - and C-domains of one subunit, and the $\mathrm{N}$-domain of an adjacent Kir6.2 subunit (Antcliff et al., 2005). Each channel contains four ATP-binding sites, yet ATP binding at a single site is sufficient to close the channel, in support of a concerted gating model (Markworth et al., 2000; Drain et al., 2004). Interestingly, however, SUR1 sensitizes Kir6.2 to ATP inhibition by about a factor of 10 (Tucker et al., 1997). This could be due to allosteric effects on Kir6.2 or facilitation of ATP binding by SUR1 (Babenko, 2005); at this point the mechanism remains unclear.

Nucleotide activation occurs at the nucleotide binding domains of SUR1 and acts to antagonize ATP inhibition (Gribble et al., 1997). The requirement of $\mathrm{Mg}^{2+}$ in this process has prompted studies to examine nucleotide interactions and hydrolysis at the NBDs. These studies led to a proposal that hydrolysis of MgATP to MgADP at NBD2, which contains the consensus ATPase site, stabilizes ATP binding at NBD1, which carries a degenerate ATPase site, and drives dimerization of the NBDs to promote channel opening at Kir6.2 (Zingman et al., 2001; Matsuo et al., 2005; Masia and Nichols, 2008). It is worth noting that direct measurements of MgATP hydrolysis using purified SUR or recombinant SUR NBDs indicate relatively poor hydrolysis efficiency (Masia et al., 2005; De Wet et al., 2007), suggesting that increased MgADP binding at NBD2 as intracellular [ADP] rises may be sufficient to induce or stabilize conformational changes at the NBDs to stimulate channel opening. Recent work by Ortiz et al. using glibenclamide binding to probe switching of the
NBDs between closed and open dimer conformations supports the notion that nucleotide hydrolysis at NBD2 is not required for conformational switch (Ortiz et al., 2012, 2013). Physiologically, the regulation of SUR1 in response to an increase in intracellu$\operatorname{lar}[\mathrm{ADP}]$ is critical for repolarizing the $\beta$-cell when glucose levels drop; without it the $\beta$-cell will be unable to stop secreting insulin. This is one common mechanism for mutations identified in SUR1 in patients with CHI (Nichols et al., 1996a; Shyng et al., 1998), who persistently secrete insulin even under severely low blood glucose levels.

Membrane phosphoinositides, such as phosphatidylinositol4,5-bisphosphate $\left(\mathrm{PIP}_{2}\right)$, and metabolic derivatives of free fatty acids, long-chain acyl-CoA esters (LC-CoAs) also have profound effects on $\mathrm{K}_{\mathrm{ATP}}$ channel gating (Baukrowitz et al., 1998; Branstrom et al., 1998; Shyng and Nichols, 1998). Both PIP 2 and LC-CoAs interact with Kir6.2 via similar mechanisms to increase channel open probability and antagonize ATP inhibition (Schulze et al., 2003). Mutagenesis studies indicate that PIP $_{2}$ and ATP may have overlapping but non-identical binding sites in Kir6.2 (Shyng et al., 2000; Cukras et al., 2002a,b; Antcliff et al., 2005). While Kir6.2 interacts directly with $\mathrm{PIP}_{2}$, SUR1 increases the sensitivity of the channel to $\mathrm{PIP}_{2}$ stimulation (Baukrowitz et al., 1998; Shyng and Nichols, 1998). Recent work by Pratt et al. shows that TMD0 of SUR1, which is known to increase the open probability of Kir6.2, does so by stabilizing the interaction between Kir6.2 and $\mathrm{PIP}_{2}$ (Pratt et al., 2011). A crucial role of $\mathrm{PIP}_{2}$ in maintaining channel activity in $\beta$-cells has been clearly demonstrated (Lin et al., 2005); mutations which disrupt the channel response to $\mathrm{PIP}_{2}$ have been identified in patients with CHI (Lin et al., 2006b, 2008). The relevance of $\mathrm{PIP}_{2}$ or LC-CoAs to physiological regulation of $K_{\text {ATP }}$ activity however, is less certain (Tarasov et al., 2004), although pathological changes in LC-CoAs have been proposed to impact channel function (Larsson et al., 1996; Riedel and Light, 2005).

\section{PHARMACOLOGICAL REGULATION OF K $\mathrm{K}_{\text {ATP }}$ CHANNELS}

An important class of agents which regulate $\mathrm{K}_{\mathrm{ATP}}$ channels are sulfonylureas (Aguilar-Bryan and Bryan, 1999; Gribble and Reimann, 2003b). Discovered in the 1940s as sulfonamide drugs that have hypoglycemic effects, sulfonylureas interact specifically with the sulfonylurea receptor SUR, giving it its namesake. Sulfonylureas have been used in the treatment of non-insulin dependent diabetes for decades, yet precisely how they promote insulin release in the body remained a mystery for years. It is now well understood that sulfonylureas bind directly to SUR1 and inhibit channel activity, thus stimulating insulin release by depolarizing the $\beta$-cell independent of glucose. Tolbutamide was part of the first generation of hypoglycemic compounds, later replaced by second-generation compounds like glibenclamide, which have 100 to 1000 -fold more potency in blocking $\mathrm{K}_{\mathrm{ATP}}$ currents. A related group of sulfonamide compounds, most notably diazoxide, also bind specifically to SUR1 but activate channels (Dunne et al., 1989; Moreau et al., 2000). Diazoxide is part of a diverse group of drugs that stimulate $\mathrm{K}^{+}$currents, known as potassium channel openers (KCOs) (Manley et al., 1993).

Although the $\mathrm{K}_{\mathrm{ATP}}$ channel was first identified in cardiac myocytes by Aki Noma in 1983 (Noma, 1983), its molecular 
identify remained uncertain for many years. Sulfonyulureas, owing to their specificity, were used as probes in the purification and cloning of $\mathrm{K}_{\mathrm{ATP}}$ channels. Early patch-clamp experiments demonstrated that sulfonylureas were specific blockers of $\beta$-cell $\mathrm{K}_{\mathrm{ATP}}$ channels, while diazoxide specifically opened them. A significant advancement came from using labeled derivatives of glibenclamide, $\left[{ }^{3} \mathrm{H}\right]$ glibenclamide (Kramer et al., 1988), and later $\left[{ }^{125} \mathrm{I}\right]$ iodoglibenclamide (Aguilar-Bryan et al., 1990), which could label a $140-\mathrm{kDa}$ protein (SUR1) in isolated membranes of various $\beta$-cell lines and led to cloning of the SUR1 gene (Aguilar-Bryan et al., 1995). Schwanstecher et al. further used ${ }^{125}$ I-iodo-azidoglibenclamide, an azido analog of glibenclamide, and found it would co-photolabel a $38 \mathrm{kDa}$ protein in addition to SUR1 and with the same apparent $\mathrm{K}_{\mathrm{D}}$ (Schwanstecher et al., 1994); this species was later identified as Kir6.2 (Inagaki et al., 1995). This provided the first evidence that the $\mathrm{K}_{\mathrm{ATP}}$ channel is a multimeric complex of Kir6.2 and SUR1.

Significant progress has since been made in defining the precise mechanism by which sulfonylureas and glinides, another class of $\mathrm{K}_{\mathrm{ATP}}$ channel inhibitors used in diabetes therapy, block $\mathrm{K}_{\mathrm{ATP}}$ channel function. All sulfonylureas and glinides demonstrate high and low-affinity components of inhibition, such that their dose-response curves are generally biphasic, with variable separation between the two sites (Gribble and Reimann, 2003a). At low concentrations, interaction with the SUR subunit results in $50-75 \%$ reduction in current amplitude when administered to the cytoplasmic face of membrane patches, suggesting that channels can remain open to an extent when bound to the drug. The low-affinity component is attributed to interaction with Kir6.2, but this only occurs at very high drug concentrations.

According to the pharmacophore model, structurally diverse compounds can possess overlapping electronic and stereochemical properties that allow them to bind a common receptor site. SUR was proposed to bind sulfonylureas accordingly with a bipartite binding pocket (Figure 3A). Consistent with this, the enhanced affinity observed in glibenclamide is attributed to interaction with the two overlapping binding sites on SUR1, termed site A and site B (Brown and Foubister, 1984). Site A is proposed to interact with a lipophilic group adjacent to the negative charge of a sulfonylurea group, while site B recognizes a lipophilic group adjacent to an amide. Glibenclamide possesses both of these moieties, while most other sulfonylureas and hypoglycemic agents such as glinides possess one or the other. Sulfonylureas are further distinguished by their ability
A

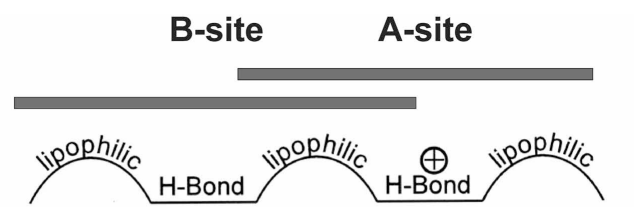

$\longrightarrow \int_{-1}^{I 1}-\mathrm{N}^{-11}$<smiles>COc1ccc(Cl)cc1C(=O)NCCc1ccc(S(=O)(=O)NC(=O)NC2CCCCC2)cc1</smiles><smiles>CCOc1cc(CC(=O)N[C@H](CC(C)C)c2ccccc2N2CCCCC2)ccc1C(=O)[O-]</smiles>

Glibenclamide

Repaglinide
B<smiles>NC(=O)N1c2ccccc2C=Cc2ccccc21</smiles>

Carbamazepine

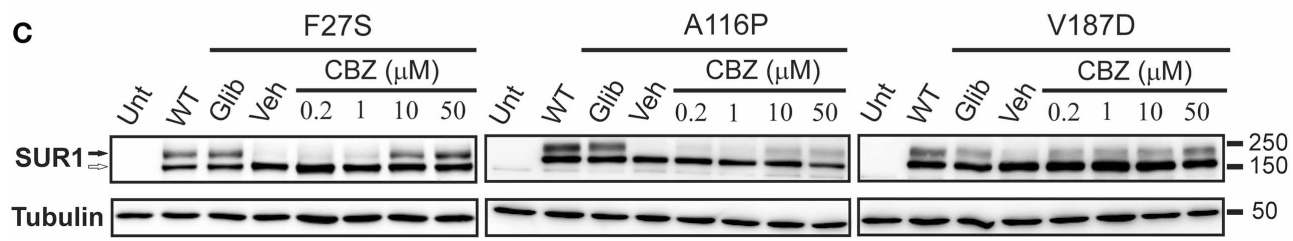

FIGURE 3 | The processing defect of SUR1 caused by TMD0 trafficking mutations is corrected by glibenclamide and carbamazepine. (A)

Pharmacophore model for binding of various $K_{\text {ATP }}$ channel blockers that function as effective pharmacological chaperones, showing the chemical moieties thought to confer affinity for either site A or site B on SUR1.

(B) Chemical structure of carbamazepine. (C) Western blot of whole cell lysates of COSm6 cells transiently transfected with Kir6.2 plus WT or TMD0 mutant SUR1 cDNAs. SUR1, a glycoprotein, shows two bands in immunoblots: a lower core glycosylated (immature; open arrow) form that has not exited the ER and an upper complex-glycosylated (mature; solid arrow) band that has trafficked through the Golgi. Incubation of cells with glibenclamide ( $5 \mu \mathrm{M}$; Glib) or carbamazepine (CBZ) for $16 \mathrm{~h}$ increased levels of the mature band of TMD0 trafficking mutants compared to those treated with DMSO (veh). The effect of carbamazepine was dose-dependent, with an effect detectable at a concentration as low as $0.2 \mu \mathrm{M}$. Untransfected control is shown for comparison. Adapted from Figure 1 in Chen et al. (2013b). 
to block either SUR1 or SUR2 $\mathrm{K}_{\text {ATP }}$ channels. Compounds that contain a non-sulfonylurea moiety (such as glibenclamide, glimepiride, repaglinide) can bind with high affinity to SUR1 and SUR2, while those with only the core sulfonylurea structure (tolbutamide, gliclizide) are specific for SUR1 (Quast et al., 2004). This difference made tolbutamide a pharmacological tool to uncover the sulfonylurea binding (A) site. Research using chimeric receptors of SUR1/SUR2 showed that TMD2 of SUR1 is critical for sulfonylurea binding. Further studies showed that mutation of S1237 of the cytoplasmic loop between TMs 15 and 16 to tyrosine (the equivalent residue in SUR2) abolished high affinity tolbutamide block and $\left[{ }^{3} \mathrm{H}\right]$ glibenclamide binding (Ashfield et al., 1999) [note that S1237 in SUR1 is now referred to as $\mathrm{S} 1238$, as current sequence information for ABCC8 (GenBank reference NM_00352.2) includes the alternate exon 17 (GenBank L78208) which contains an additional amino acid]. Further, the reciprocal mutation in SUR2 (Y1206S) increased $\left[{ }^{3} \mathrm{H}\right]$ glibenclamide binding by roughly 10 -fold. Mapping of site B in SUR1 came from a study examining affinity labeling with $\left[{ }^{125} \mathrm{I}\right]$ iodoglibenclamde which identified a $\sim 50 \mathrm{kDa}$ fragment including TMD0-L0 (Bryan et al., 2004). A more precise definition came from Vila-Carriles et al. by using deletions and alanine scanning in TMD0 and L0 of SUR1 to monitor photolabeling by $\left[{ }^{125} \mathrm{I}\right]$ azido-iodoglibenclamide (Vila-Carriles et al., 2007). The authors concluded that L0 of SUR1 is absolutely essential for glibenclamide binding, while TMD0 is nonessential. Scanning alanine mutations showed that Y230 and W232 are critical for high affinity photolabeling. Further, they determined that the Nterminal 33 amino acids of Kir6.2 are involved in site B labeling by $\left[{ }^{125} \mathrm{I}\right]$ azido-iodoglibenclamide. Together, these results indicate that site A (TMD2) and site B (L0) are within close physical proximity such that they can cooperatively bind glibenclamide, and that the N-terminus of Kir6.2 also forms part of the site B binding pocket.

\section{PHARMACOLOGICAL REGULATION OF K KTP CHANNEL TRAFFICKING DEFECTS}

Over the past 10 years, it has been recognized that, in addition to their action as specific $\mathrm{K}_{\mathrm{ATP}}$ channel blockers, sulfonylureas also promote the proper folding and biogenesis of traffickingimpaired mutant SUR1 proteins identified in patients with $\mathrm{CHI}$ by acting as pharmacological chaperones. They achieve this with domain specificity, only rescuing mutations within TMD0 of SUR1. In principle, this opened up a new therapeutic avenue for sulfonylureas, in which they could be administered to patients with TMD0 trafficking mutations and rescue $\mathrm{K}_{\mathrm{ATP}}$ channel function in $\beta$-cells. Sulfonylureas are imperfect correctors, however, as they often irreversibly block channel function of rescued mutant channels. This is an unsuitable therapeutic approach for treating diseases like $\mathrm{CHI}$, which require functional channels at the cell surface in order to limit insulin release and restore blood glucose to normal levels. Recently, additional new compounds such as carbamazepine (CBZ) (Figure 3B), which also correct traffickingimpaired $\mathrm{K}_{\mathrm{ATP}}$ channels with mutations in TMD0 of SUR1 without the irreversible block observed with glibenclamide, have been identified. As discussed below, in vitro studies with pharmacological chaperones have increased our understanding of how certain
$\mathrm{K}_{\mathrm{ATP}}$ channel mutations lead to disease, strengthening the link between genotype and phenotype, while also highlighting general principles involved in the gating and molecular assembly of heteromeric ion channels, like $\mathrm{K}_{\mathrm{ATP}}$.

\section{$K_{\text {ATP }}$ CHANNEL TRAFFICKING DEFECTS IN HUMAN DISEASE}

Proper cellular function relies on both the absolute number and subcellular localization of many proteins; this is particularly true of membrane proteins like $\mathrm{K}_{\mathrm{ATP}}$. For ion channels and other membrane or secreted proteins, translation begins in the cytosol but soon becomes associated with the endoplasmic reticulum (ER). Here it is thought the bulk of protein folding and quaternary assembly take place. This occurs under the auspices of an array of molecular chaperones, integral members of the ER quality control system, which ensure the proper folding, processing, and structural integrity of nascent proteins while preventing the accumulation of defective proteins which may disrupt normal cell function. Trafficking mutations can interfere with this process by disrupting protein folding and molecular assembly in the ER, generally leading to retention and clearance of mutant proteins through ERAD.

Mislocalization of cell-surface proteins which are otherwise functional has been demonstrated in numerous diseases, including CF, familial hypercholesteremia, retinitis pigmentosa, and diabetes insipidus (Powers et al., 2009). In CF, the $\Delta$ F508 deletion (present in 90\% of CF patients) in CFTR leads to ER retention and rapid degradation of the incompletely processed protein by the proteasome (Jensen et al., 1995; Ward et al., 1995). Insufficient levels of this chloride channel at the cell surface prevent cAMPmediated chloride ion, water, and bicarbonate conductance in a variety of tissues. More recently, it has been established that point mutations in the genes encoding the $\mathrm{K}_{\mathrm{ATP}}$ channel subunits can also interfere with or prevent proper folding and/or molecular assembly in the ER (Table 1). These mutations are found throughout the SUR1 and Kir6.2 proteins. Normal levels of protein are usually translated, but mutant proteins are unable to exit the ER, and as with $\triangle$ F508-CFTR and many other conformationally-defective proteins, are degraded through the ubiquitin/proteasome pathway. $\mathrm{K}_{\mathrm{ATP}}$ channel trafficking mutations have since been shown to be a common mechanism in CHI (Cartier et al., 2001; Taschenberger et al., 2002; Crane and Aguilar-Bryan, 2004; Tornovsky et al., 2004; Yan et al., 2004, 2007; Marthinet et al., 2005; Muzyamba et al., 2007; Fukuda et al., 2011; Powell et al., 2011; Faletra et al., 2013), in which loss of $K_{A T P}$ channels at the cell surface results in unregulated insulin secretion following constitutive depolarization of the $\beta$-cell.

Among the mutations documented, A116P- and V187DSUR1, both located in TMD0, exhibited reduced association with Kir6.2 in co-immunoprecipitation experiments (Chan et al., 2003), supporting a role of TMD0 in subunit-subunit interactions. Further, $\Delta$ F1388-, A116P-SUR1 and W91R-Kir6.2 all showed accelerated degradation (Crane and Aguilar-Bryan, 2004; Yan et al., 2004, 2005). These observations are consistent with the mutant proteins being misfolded and/or unable to form channel complexes. Of note, the aforementioned studies were all conducted in mammalian cells rather than Xenopus oocytes as oocytes cultured at a lower temperature have less stringent 
Table 1 | Congenital Hyperinsulinism-associated $K_{\text {ATP }}$ channel trafficking mutations and response to pharmacological rescue ${ }^{1}$.

\begin{tabular}{|c|c|c|c|c|c|}
\hline Mutation & Domain & $\begin{array}{l}\text { Rescue } \\
\text { by SU }\end{array}$ & $\begin{array}{l}\text { Rescue } \\
\text { by CBZ }\end{array}$ & $\begin{array}{l}\text { Gating } \\
\text { property }\end{array}$ & References \\
\hline \multicolumn{6}{|l|}{ SUR1 } \\
\hline G7R & TMD0 & Yes & Yes & Normal & Yan et al., 2007 \\
\hline N24K & TMD0 & Yes & Yes & Normal & Yan et al., 2007 \\
\hline F27S & TMDO & Yes & Yes & Normal & Yan et al., 2007 \\
\hline $\mathrm{R} 74 \mathrm{~W}$ & TMD0 & Yes & Yes & $\begin{array}{l}\text { ATP- } \\
\text { insensitive }\end{array}$ & Yan et al., 2007 \\
\hline A116P & TMDO & Yes & Yes & Normal & Yan et al., 2004 \\
\hline E128K & TMDO & Yes & Yes & $\begin{array}{l}\text { ATP- } \\
\text { insensitive }\end{array}$ & Yan et al., 2007 \\
\hline V187D & TMDO & Yes & Yes & Normal & Yan et al., 2004 \\
\hline R4950 & TMD1 & Yes & Yes & Unknown & Yan et al., 2007 \\
\hline E501K & TMD1 & Yes & Yes & Unknown & Yan et al., 2007 \\
\hline L503P & TMD1 & No & No & Unknown & Yan et al., 2007 \\
\hline F686S & NBD1 & No & No & Unknown & Yan et al., 2007 \\
\hline G716V & NBD1 & No & No & Unknown & Yan et al., 2007 \\
\hline E1324K & TMD2 & N.D. ${ }^{3}$ & N.D. & Normal & $\begin{array}{l}\text { Faletra et al., } \\
2013\end{array}$ \\
\hline L13500 & NBD2 & No & No & Unknown & Yan et al., 2007 \\
\hline$\Delta \mathrm{F} 1388^{2}$ & NBD2 & No & No & $\begin{array}{l}\text { MgADP- } \\
\text { insensitive }\end{array}$ & $\begin{array}{l}\text { Cartier et al., } \\
2001\end{array}$ \\
\hline M1395R & NBD2 & N.D. & N.D. & Unknown & $\begin{array}{l}\text { Faletra et al., } \\
2013\end{array}$ \\
\hline $\mathrm{R} 1419 \mathrm{H}$ & NBD2 & No & No & Unknown & $\begin{array}{l}\text { Tornovsky et al., } \\
2004\end{array}$ \\
\hline R14370 & NBD2 & No & No & Unknown & $\begin{array}{l}\text { Muzyamba } \\
\text { et al., } 2007\end{array}$ \\
\hline $\mathrm{D} 1472 \mathrm{H}$ & NBD2 & No & No & Unknown & Yan et al., 2007 \\
\hline R1494W & NBD2 & No & No & Unknown & $\begin{array}{l}\text { Tornovsky et al., } \\
2004\end{array}$ \\
\hline L1544P2 & NBD2 & No & No & $\begin{array}{l}\text { MgADP- } \\
\text { insensitive }\end{array}$ & $\begin{array}{l}\text { Taschenberger } \\
\text { et al., } 2002\end{array}$ \\
\hline \multicolumn{6}{|l|}{ Kir6.2 } \\
\hline W91R & M1 & N.D. & N.D. & Unknown & $\begin{array}{l}\text { Crane and } \\
\text { Aguilar-Bryan, } \\
2004\end{array}$ \\
\hline $\mathrm{H} 259 \mathrm{R}$ & C-term & N.D. & N.D. & Unknown & $\begin{array}{l}\text { Marthinet et al., } \\
2005\end{array}$ \\
\hline E282K & C-term & N.D. & N.D. & Unknown & $\begin{array}{l}\text { Taneja et al., } \\
2009\end{array}$ \\
\hline R301G & C-term & N.D & N.D & Inactivation ${ }^{4}$ & Lin et al., 2008 \\
\hline $\mathrm{R} 301 \mathrm{H}$ & C-term & N.D & N.D & Inactivation & Lin et al., 2008 \\
\hline R301P & C-term & N.D & N.D & Inactivation & Lin et al., 2008 \\
\hline
\end{tabular}

${ }^{1}$ Only published mutations that have been tested for surface expression are included.

${ }^{2}$ These mutations were rescued to the cell surface by mutating the RKR ER retention signal to $A A A$.

${ }^{3}$ N.D.: Not determined.

${ }^{4}$ Inactivation: Spontaneous current decay in the absence of inhibitory ATP.

ER quality control and allow surface expression of mutant channels that would otherwise be retained intracellularly (Drumm et al., 1991). In addition to protein misfolding, recently a Kir6.2 mutation E282K identified in a case of histological focal CHI (due to combination of a paternal $\mathrm{K}_{\mathrm{ATP}}$ mutation and clonal loss of heterozygosity of $11 \mathrm{p} 15)$ was reported to diminish surface expression of $\mathrm{K}_{\mathrm{ATP}}$ channels by disrupting a di-acidic ER exit signal in Kir6.2 involved in concentration of the channel protein into COPII vesicles without affecting channel protein folding (Taneja et al., 2009). Also, the SUR1 mutation R1394H reportedly causes retention of the channel in the Golgi compartment of HEK239 cells, thereby preventing surface expression (Partridge et al., 2001). Although increased internalization and degradation of surface channels may also reduce the number of channels at the cell surface no such examples have been reported.

\section{CORRECTION OF K $\mathrm{ATP}_{\text {CHANNEL TRAFFICKING DEFECTS BY }}$ PHARMACOLOGICAL CHAPERONES}

The discovery that protein misfolding is an important cause of various diseases has prompted intense investigation into ways of overcoming the biogenesis defect as a means of therapy (Powers et al., 2009). A key finding came from Denning et al, who showed that cells expressing $\triangle$ F508-CFTR had greater surface levels of the channel when grown at reduced temperature (Denning et al., 1992). This demonstrated that manipulation of the cellular folding environment can positively impact the biogenesis of proteins. Certain exogenous compounds, like glycerol or DMSO, were also shown to enhance the expression of trafficking-impaired proteins, acting as chemical chaperones (Brown et al., 1996). It is thought these compounds interact directly with the protein during folding and assembly in the ER and impact biogenesis by one or several of the following mechanisms: (1) reducing degradation by thermodynamically stabilizing a misfolded conformation of the protein; (2) increasing the folding rate by stabilizing a folding intermediate; (3) decreasing the misfolding rate by stabilizing the native state. Alternatively, chemical chaperones could indirectly affect biogenesis of proteins by interacting with endogenous molecular chaperones in the ER.

Chemical chaperones, such as glycerol, are nonspecific, however, and enhance the expression of multiple proteins in a cell. In a seminal study, Loo et al. demonstrated that pharmacological ligands can specifically promote the stability and expression of trafficking-impaired mutant isoforms of P-glycoprotein (P-gp), a multidrug resistant protein (Loo and Clarke, 1997). Multiple drug compounds known to directly interact with P-gp rapidly enhanced expression of various engineered P-gp trafficking mutants in a dose-dependent manner, producing functional proteins at the plasma membrane. These results were soon echoed by various other groups using high-affinity ligands for lysosomal $\alpha$-galactosidase A (Fan et al., 1999), the $V_{2}$ vasopressin receptor (Morello et al., 2000), the HERG (human ethera-go-go-related gene) potassium channel (Zhou et al., 1999), among others. An emerging theme began to develop in which specific chemical chaperones, termed pharmacological chaperones, could be administered therapeutically in order to reverse trafficking defects found in patients with complex diseases. High-throughput screens have identified more advanced compounds which can rescue mutants with more subtle trafficking defects. Several promising hits are currently undergoing clinical trials for treatment of lysosomal storage diseases, including Fabry's, Pombe's, Tay-Sachs, and Gaucher's diseases, as well as CF. Discussed below are recent studies describing the functional 
restoration of trafficking-impaired $\mathrm{K}_{\mathrm{ATP}}$ channels with the use of small molecule correctors. These studies have added to our fundamental understanding of the biogenesis of $\mathrm{K}_{\mathrm{ATP}}$ channels while bringing forth a new therapeutic route for treating CHI. Further, they have led to new understanding in the ways that pharmacological ligands interact with $\mathrm{K}_{\mathrm{ATP}}$ channels and impact their function.

\section{CORRECTION OF K KTP CHANNEL TRAFFICKING DEFECTS BY SULFONYLUREAS}

As with many diseases, a major challenge has been to define how mutations in $\mathrm{K}_{\mathrm{ATP}}$ channel subunits associated with $\mathrm{CHI}$ promote disease. Some mutant channels had been shown to be unresponsive to MgADP stimulation (Nichols et al., 1996b; Shyng et al., 1998; Snider et al., 2013), while others produce nonfunctional truncated proteins due to insertion of a stop codon (Nestorowicz et al., 1997, 1998). An important discovery came from Cartier et al., who showed that one $\mathrm{K}_{\mathrm{ATP}}$ channel mutation identified in CHI, $\triangle \mathrm{F} 1388$ in SUR1, prevented surface expression of the channel when expressed in COS cells (Cartier et al., 2001). Interestingly, functional channel complexes were observed when the ER retention signal RKR in $\triangle F 1388$-SUR1 was mutated to AAA, which can often allow some trafficking-impaired proteins to escape the ER. This placed some forms of CHI now in the same category as CF and other protein misfolding diseases, whereby loss-of-function results from mislocalization of mutant proteins. Subsequent work identified additional SUR1 mutations in CHI patients that impair the proper trafficking of $\mathrm{K}_{\mathrm{ATP}}$ channels, including L1544P, A116P, and V187D (Taschenberger et al., 2002; Yan et al., 2004).

The successful use of pharmacological ligands in correcting trafficking defects of other membrane proteins prompted several groups to apply that same principle to trafficking-impaired $\mathrm{K}_{\text {ATP }}$ channels. Yan et al. (2004) demonstrated that two CHI mutations, A116P and V187D, both located in the first transmembrane domain TMD0 of SUR1, could be rescued by sulfonylureas in vitro. Functional study of mutant channels rescued to the cell surface by the reversible sulfonylurea tolbutamide revealed normal sensitivity to MgADP and ATP once tolbutamide was washed out, suggesting that trafficking mutations may not interfere with channel function. Presumably, as is the case for pharmacological rescue of other trafficking-impaired proteins, sulfonylureas facilitate the biogenesis of these SUR1 mutants by interacting with the protein directly during folding and assembly in the ER. Yet an understanding of the mechanism of the trafficking impairment is key to grasping the mechanism of recovery. Previously, Chan et al. showed that TMD0 domain of SUR1 harboring the A116P or V187D mutation, had reduced association with Kir6.2 in coimmunoprecipitation experiments (Chan et al., 2003). As TMD0 is known to mediate interactions between SUR1 and Kir6.2, it is reasonable to assume that mutations in TMD0 disrupt these subunit interactions and prevent channel trafficking out of the ER. Yan et al. showed, however, that the trafficking defect in A116P and V187D is intrinsic to SUR1. This is based on the observation that in the absence of Kir6.2, A116P and V187D also prevented Kir6.2-independent surface expression of a SUR1 protein in which the RKR ER retention signal is inactivated by mutation to AAA (SUR1 $1_{\mathrm{AAA}}$ ). Another potential explanation for the trafficking defect is that these mutations may prevent proper shielding of the RKR ER retention signals that must occur during assembly in the ER, as has been demonstrated for the L1544P mutation (Taschenberger et al., 2002). Yet mutation of these signals in both subunits also failed to improve surface expression of the A116P or V187D mutants. These results suggest that SUR1 misfolding, which also likely adversely affects association with Kir6.2, prevents exit of these mutants from the ER. Consistent with this notion, channel trafficking defects caused by A116P and V187D could be overcome by culturing cells at lower temperature (Yang et al., 2005), a condition known to facilitate protein folding. Metabolic pulse-chase experiments demonstrated that glibenclamide slowed A116P-SUR1 degradation even in the absence of Kir6.2 and promoted maturation of the mutant SUR1 when Kir6.2 was co-expressed (Yan et al., 2004), providing evidence that sulfonylureas facilitate folding and/or prevent misfolding of mutant channels during assembly in the ER.

The question remained, however, of whether sulfonylureas act as true pharmacological chaperones by promoting biogenesis through direct binding of the channel. Compelling evidence came from a study showing that mutation of residues critical for sulfonylurea and glinide binding abolished or reduced these compounds' ability to rescue $\mathrm{K}_{\mathrm{ATP}}$ channel trafficking mutants (Yan et al., 2006). Binding of tolbutamide, a first generation sulfonylurea, has been shown to depend on S1238 in SUR1, representing site A (Ashfield et al., 1999). Accordingly, mutation of S1238 to tyrosine abolished tolbutamide rescue of SUR1 mutants A116P and V187D. Glibenclamide binding involves both site A (S1238) and site B, which includes residue Y230 (Bryan et al., 2004). Mutation of either site A (S1238Y) or site B (Y230A) diminished glibenclamide's rescue effect, while simultaneous mutation of both completely abolished it, suggesting that the sulfonylurea and benzamido moieties both contribute to the rescue effect of glibenclamide. Interestingly, the site B mutation Y230A, in addition to attenuating the effect of glibenclamide and abolishing the effect of rapaglinide, also rendered tolbutamide ineffective at rescuing mutant channels. This suggests that either Y230 is involved in tolbutamide binding or Y230 is necessary for post-binding events involved in tolbutamide rescue, such as coupling of SUR1 and Kir6.2 subunits. In support of the latter, Y230 has been shown to be in close proximity to the $\mathrm{N}$-terminus of Kir6.2 (Vila-Carriles et al., 2007). Further, deletion of the Kir6.2 N-terminus abolishes tolbutamide channel block in membrane patches (Koster et al., 1999; Reimann et al., 1999), suggesting a functional interface at Y230 of SUR1 and the N-terminus of Kir6.2 that couples tolbutamide binding to changes in channel activity. The results of S1238Y and/or Y230A mutants on the ability of sulfonylureas to rescue $\mathrm{K}_{\mathrm{ATP}}$ trafficking mutants were also in parallel to their ability to block channel activity. Thus, there is likely a common mechanism in transducing ligand binding to functional outcome. Finally, a key finding from this study is that sulfonylureas act on the channel complex, rather than SUR1 alone, to restore surface expression of trafficking mutants, as pharmacological rescue by sulfonylureas is dependent on Kir6.2. Expression of either A116P $\mathrm{P}_{\mathrm{AAA}}$-SUR1 or V187D $\mathrm{DAA}_{\mathrm{A}}$-SUR1, which lack the RKR ER retention motif, could not be rescued without co-expression of 
Kir6.2. The requirement of Kir6.2 for the rescue effect could be explained by the involvement of Kir6.2 in sulfonylurea binding to SUR1; alternatively, Kir6.2 could participate in the tertiary folding of mutant SUR1 subunits.

An interesting trend noted for all $\mathrm{K}_{\mathrm{ATP}}$ trafficking mutants tested thus far is that only mutations within TMD0 of SUR1 are amenable to pharmacological rescue by sulfonylureas (Table 1). TMD0, the first of three transmembrane domains in SUR1, is a unique structural feature not shared by most $\mathrm{ABC}$ transporters, including CFTR or P-gp, which contain only TMD1 and TMD2. When expressed alone, TMD0 has been shown to physically associate with Kir6.2 and both facilitate its expression and modulate its gating function, making this domain a distinct functional entity (Babenko and Bryan, 2003; Chan et al., 2003). The studies described above demonstrate that sulfonylureas exert chaperoning effects by binding regions downstream of TMD0. Thus, ligand binding to the core ABC structure is likely translated into structural and functional outcomes at TMD0 to overcome trafficking defects caused by mutations within this region. Such substrateinduced transmembrane domain interactions have been reported previously: in human P-gp, also an ABC transporter, substrate binding promoted superfolding of partially folded intermediates via interactions between the two transmembrane domains TMD1 and TMD2 (Loo and Clarke, 1998). As such, a likely mechanism for the pharmacological chaperone effect is that sulfonylurea binding to the SUR1/Kir6.2 complex induces structural changes in TMD0 that restore functional interactions between SUR1 and Kir6.2, allowing trafficking of the channel out of the ER. The precise nature of the interface between TMD0 and Kir6.2 is unclear, however. Interestingly, a recent study by Zhou et al. showed that a point mutation in Kir6.2, Q52E, located in the N-terminus of the protein just before the slide helix, partially compensated for the trafficking defects caused by SUR1-TMD0 mutations F27S and A116P, indicating that altered molecular interactions with Kir6.2 can overcome impaired channel folding/assembly caused by TMD0 mutations (Zhou et al., 2013). An understanding of how these domains are interacting will provide valuable insight into not only the mechanism of pharmacological rescue, but also how physiological or pharmacological interactions at SUR1 are coupled to changes in channel activity at Kir6.2.

\section{CORRECTION OF K $K_{\text {ATP }}$ CHANNEL TRAFFICKING DEFECTS BY $\triangle$ F508-CFTR CORRECTORS, IN PARTICULAR BY CARBAMAZEPINE}

The fact that multiple TMD0 trafficking mutants have normal responses to metabolic signals and pharmacological ligands provides proof of principle that pharmacological rescue is a therapeutically viable alternative to the current treatment for many $\mathrm{CHI}$ with such mutations, which often relies on partial or near complete removal of the pancreas. Translation of these findings, however, has been hindered by the pharmacology of glibenclamide, the most effective sulfonylurea at rescuing traffickingimpaired $\mathrm{K}_{\mathrm{ATP}}$ channels. SUR1 binds glibenclamide with high affinity and slow dissociation kinetics, resulting in an irreversible block on channel function; rescued channels would therefore be unable to hyperpolarize the $\beta$-cell in order to attenuate insulin release. Tolbutamide, another sulfonylurea that effectively rescues multiple TMD0 trafficking mutants, binds $\mathrm{K}_{\mathrm{ATP}}$ channels reversibly. A study released by the University Group Diabetes Program, however, implicated tolbutamide in increased mortality secondary to cardiovascular events (Schwartz and Meinert, 2004). Thus, in terms of therapy, there is a need for additional compounds that promote robust recovery of $\mathrm{K}_{\mathrm{ATP}}$ channel trafficking mutants and bind reversibly, but are also safe for administration to patients.

Like trafficking-impaired $\mathrm{K}_{\mathrm{ATP}}$ channels in CHI, $\triangle$ F508-CFTR causes partial misfolding of the channel and clearance through the ubiquitin/proteasome pathway, resulting in CF. Much effort has been devoted to identifying small molecules that correct this trafficking defect, and high-throughput drug screens have yielded several promising compounds (Pedemonte et al., 2005; Carlile et al., 2007). As CFTR and SUR1 are both members of the $\mathrm{ABC}$ transporter superfamily and have common structural features in the $\mathrm{ABC}$ core domain, it is reasonable to hypothesize that small molecules which correct folding and trafficking defects in $\triangle$ F508-CFTR might also rescue traffickingimpaired $\mathrm{K}_{\mathrm{ATP}}$ channels caused by mutations in SUR1. Powell et al. first reported the effects of compounds known to stimulate CFTR trafficking on human $\beta$-cells lacking functional $\mathrm{K}_{\mathrm{ATP}}$ currents from $\mathrm{CHI}$ patients harboring various $A B C C 8$ mutations (Powell et al., 2011). Although it remains unknown how these mutations impact channel trafficking and gating to cause loss of channel activity, the study demonstrated that a $\Delta$ F508CFTR corrector, 4-phenylbutyrate, could recover activities of $\mathrm{K}_{\mathrm{ATP}}$ channels in $\beta$-cells isolated from a patient bearing the SUR1 compound heterozygous mutation Arg998X/Ser1449dup (Powell et al., 2011). Additionally, the study showed that incubation of $\beta$-cells from another patient bearing homozygous $A B C C 8$ intronic mutation $c .1467+5 \mathrm{G}>\mathrm{A}$ with a combination of 3-isobutyl-1-methylxanthine (IBMX), forskolin, and phorbol myristic acid (PMA), compounds expected to activate PKA and $\mathrm{PKC}$, for $1 \mathrm{~h}$ also led to increased channel activity. Because PKA activation has been reported to promote trafficking of several ion channels to the cell surface whereas PKC activation has been reported to reduce surface $\mathrm{K}_{\mathrm{ATP}}$ expression by diverting endocytosed channels to lysosomal degradation (Manna et al., 2010), the authors speculate that the positive effect of PKA activation likely overrides the negative effects of PKC to lead to an overall increase in surface expression of $\mathrm{K}_{\mathrm{ATP}}$ channels (Powell et al., 2011). It is interesting to note that a role of PKA in $K_{\text {ATP }}$ channel trafficking has indeed been reported. A study by Yang et al. showed that glucose stimulation recruits $\beta$-cell $\mathrm{K}_{\mathrm{ATP}}$ channels to the cell surface in a PKA-dependent manner (Yang et al., 2007). In addition, Chen et al. showed that PKA activation promotes $\mathrm{K}_{\text {ATP }}$ channel trafficking to the surface in INS-1 rat insulinoma cells by promoting F-actin depolymerization without affecting overall channel protein levels (Chen et al., 2013a). The findings by Powell et al. will undoubtedly stimulate future research to harness the therapeutic potential of these compounds and to understand the molecular mechanisms by which these molecules restore functional expression of $\mathrm{K}_{\mathrm{ATP}}$ channels in $\mathrm{CHI}$ patients.

A more recent study by Sampson et al. tested the effects of multiple CFTR correctors identified in a chemical library screen (Carlile et al., 2007) on the processing efficiency of two SUR1 trafficking mutants, A116P and V187D (Sampson et al., 2013). 
Among the compounds that improved the processing efficiency of the two mutant SUR1 proteins is the drug carbamazepine (CBZ). CBZ has been used for decades in the treatment of epilepsy, neuropathic pain, as well as mental illnesses like bipolar disorder. CBZ has a well-documented role as a sodium channel blocker, but studies have shown effects on calcium channels as well as GABA receptors (Ambrosio et al., 2002). Our group focused attention on $\mathrm{CBZ}$ as a potential pharmacological chaperone for SUR1 trafficking mutants, as it is approved by the Food and Drug Administration and has an established biosafety profile. In a recent report we demonstrated that CBZ effectively rescues multiple $\mathrm{K}_{\mathrm{ATP}}$ trafficking mutations previously identified in CHI (Chen et al., 2013b) (Figure 3C). Interestingly, as with sulfonylureas, only mutations present in TMD0 of SUR1 were amenable to pharmacological rescue by CBZ. This suggests sulfonylureas and CBZ may act through a common mechanism to enhance surface expression of trafficking mutants, such as by stabilizing interactions between TMD0 and Kir6.2. There are studies showing, however, that CBZ can induce autophagy to facilitate clearance of misfolded protein aggregates (Sarkar et al., 2007; Hidvegi et al., 2010), which could in turn alleviate ER stress and promote surface expression of trafficking mutants. This raises the possibility that $\mathrm{CBZ}$ may enhance surface expression of TMD0 trafficking mutants not by acting as a pharmacological chaperone but by inducing autophagy. Disfavoring this idea, inhibition of autophagy by chloroquine or Ly294002 did not block CBZ's ability to rescue $\mathrm{K}_{\mathrm{ATP}}$ trafficking mutants. Moreover, stimulation of autophagy by rapamycin or $\mathrm{Li}^{+}$did not enhance mutant $\mathrm{K}_{\mathrm{ATP}}$ channel processing or expression. These results indicate that CBZ most likely rescues mutant channels through an autophagy-independent pathway.

A surprising and intriguing finding by Chen et al. is that CBZ inhibits the activity of mutant channels rescued to the cell surface, as demonstrated in ${ }^{86} \mathrm{Rb}^{+}$efflux experiments. Subsequent electrophysiology experiments showed that CBZ inhibits channel activity when applied to the cytoplasmic face of isolated membrane patches containing wild-type $\mathrm{K}_{\mathrm{ATP}}$ channels. These observations suggest that CBZ may act as a $\mathrm{K}_{\mathrm{ATP}}$ channel antagonist, like sulfonylureas. Further characterization of the inhibitory effect of CBZ by ${ }^{86} \mathrm{Rb}^{+}$efflux assays showed that the function of rescued mutant channels could be completely recovered after extensive washout $(\sim 90 \mathrm{~min})$, similar to that observed for the reversible, low-affinity sulfonylurea tolbutamide but not the irreversible high affinity sulfonylurea glibenclamide (Yan et al., 2004). Because the effect of CBZ on mutant channel trafficking could be detected at a concentration as low as $0.2 \mu \mathrm{M}$ (Chen et al., 2013b) (see Figure 3C), it is conceivable that low doses of CBZ could be used to rescue mutant channels to the cell surface without potent inhibition of channel activity. Another approach to circumvent the problem of chaperone inhibitors may be to simultaneously apply correctors and compounds that boost the function of rescued proteins, referred to as potentiators (Rowe and Verkman, 2013). Indeed, we have found that while diazoxide is unable to activate channels rescued by the irreversible antagonist glibenclamide, it significantly increased the activity of channels rescued by $\mathrm{CBZ}$ in Rb efflux assays. In these experiments, CBZ was not included in the 40-min efflux period so some CBZ was likely to have dissociated from the rescued channels, as evidenced by a small increase in efflux even without diazoxide; however, inclusion of diazoxide during efflux further increased channel activity, indicating that diazoxide can facilitate functional recovery of $\mathrm{CBZ}$ rescued channels. Clinically, this has important implications, as it has been proposed that small changes in $\mathrm{K}_{\mathrm{ATP}}$ channel activity are correlated with large differences in clinical outcome (Macmullen et al., 2011). Interestingly, we have found that diazoxide precludes glibenclamide's ability to rescue $\mathrm{K}_{\mathrm{ATP}}$ trafficking mutants, while it has no effect on the rescue of mutant channels by CBZ when the drugs are co-administered. This further supports the clinical feasibility of a combination therapy using a pharmacological chaperone and a channel activator to alleviate symptoms in patients with CHI. Also important, the effects of CBZ were observed in two physiologically relevant systems, namely the rat $\beta$-cell line INS-1 and freshly isolated primary human $\beta$-cells. Further, the concentrations at which CBZ is effective at rescuing TMD0 trafficking mutants $(10-50 \mu \mathrm{M})$ is similar to those used to block $\mathrm{Na}^{+}$channels, suggesting the approved dosage prescribed for $\mathrm{CBZ}$ will impact $\mathrm{K}_{\mathrm{ATP}}$ channel expression. These data make a compelling case for further exploration of $\mathrm{CBZ}$ as a potential treatment for patients with certain forms of $\mathrm{CHI}$.

Besides therapeutic implications, CBZ and glibenclamide differ markedly in their chemical structures and yet both rescue the expression of only those $\mathrm{K}_{\mathrm{ATP}}$ channels with trafficking mutations in TMD0 of SUR1 and both inhibit $\mathrm{K}_{\mathrm{ATP}}$ channel activity. An intriguing question to address in the future is whether the closed channel conformation rendered by these ligands represents a state that favors forward trafficking.

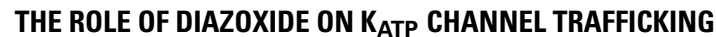

Ideally, a pharmacological chaperone would correct protein trafficking defects without compromising or even enhance protein function. In this regard, it is worth noting that the $\mathrm{K}_{\mathrm{ATP}}$ channel opener diazoxide has been reported to correct channel trafficking defects caused by the SUR1 mutations R1394H (Partridge et al., 2001). Using a stable HEK293 cell line co-expressing wildtype or R1394H His-tagged hamster SUR1 and Kir6.2 tagged at the C-terminus with a HMA (heart muscle kinase phosphorylation site)-FLAG epitope, Partridge et al. showed that the mutant SUR1 failed to reach the cell surface and instead accumulated in the trans-Golgi network, and that diazoxide was able to restore surface expression of the R1394H mutant SUR1. However, a subsequent study by Yan et al. using FLAG-tagged R1394H mutant hamster SUR1 transiently co-expressed with Kir6.2 in COS cells reported normal trafficking of the mutant to the cell surface (Yan et al., 2004). Whether these different results are due to the different constructs or cells used remain to be resolved. Aside from the $\mathrm{R} 1394 \mathrm{H}$ mutation reported by Partridge et al., no other known trafficking mutations tested so far are rescued by diazoxide (Yan et al., 2004, 2007; Chen et al., 2013b). Also worth noting, Powell et al. showed that a diazoxide analog BPDZ 154 restored ATP-inhibited channel activity in human $\beta$-cells from a $\mathrm{CHI}$ patient with the homozygous $A B C C 8$ intronic mutation c. $1467+5 \mathrm{G}>\mathrm{A}$ after $24-48 \mathrm{~h}$ incubation. Since it is not clear how this intronic mutation affects channel trafficking and/or function, it remains to be determined whether 
BPDZ 154 enhances channel trafficking and/or gating to restore function.

\section{INTERPLAY BETWEEN CHANNEL EXPRESSION AND GATING IN DISEASE MANIFESTATION}

Although some TMD0 mutations only impair channel trafficking such that pharmacological rescue of mutant channels to the cell surface is expected to partially or fully restore channel function, some impact both channel biogenesis and gating as exemplified by the R74W and E128K mutations (Pratt et al., 2009). These mutations result in $\mathrm{CHI}$ by preventing channel expression at the cell surface. Upon rescue to the cell surface by tolbutamide followed by washout, mutant channels exhibit reduced sensitivity to ATP inhibition, a gating defect commonly observed in gain-of-function mutations associated with permanent neonatal diabetes (PNDM). Detailed analysis revealed that these two mutations cause functional uncoupling between SUR1 and Kir6.2 by impairing the ability of SUR1 to hypersensitize Kir6.2 channels to ATP inhibition (Pratt et al., 2011). When these mutations were introduced into the insulinoma cells INS-1 and rescued to the cell surface by tolbutamide, subsequent washout of tolbutamide led to cells with more hyperpolarized membrane potential in the face of glucose stimulation (Pratt et al., 2009), similar to $\beta$-cells with gain-of-function, diabetes-causing mutant $\mathrm{K}_{\mathrm{ATP}}$ channels.

Intuitively, trafficking defects are associated with loss of channel function and the disease CHI. However, it has been shown that many mutations identified in PNDM (Gloyn et al., 2004; Proks et al., 2004, 2005, 2006; Koster et al., 2005) also reduce channel biogenesis efficiency, including Q52R, V59G/M, R201C/H and I296L in Kir6.2 (Lin et al., 2006a) as well as F132L in SUR1 (Pratt et al., 2009) when expressed heterologously as homomeric mutant channels (Table 2). It is interesting that glibenclamide was also found to significantly improve surface expression of heterologously expressed homomeric mutant channels (Lin et al., 2006a), again hinting at SUR1-Kir6.2 interactions in sulfonylurea-mediated rescue. Whether CBZ also improves surface expression of these PNDM mutations remains to be determined. Because these PNDM mutations are dominant, heterozygous mutations with severe gating defects, a mutant channel subunit can exert its gain-of-function gating effect by co-assembly with the WT allele. In this scenario, the extent of expression of mutant subunit in the cell surface channel population may determine the extent of overall channel gating defect and thus, disease severity as has been proposed for several PNDM mutations, including V324M in SUR1 (Zhou et al., 2010) as well as C42R and Pro226-Pro232 deletion mutation in Kir6.2 (Yorifuji et al., 2005; Lin et al., 2013).

The above studies highlight the importance of the interplay between channel expression and gating defects in determining disease phenotype. As $\mathrm{K}_{\mathrm{ATP}}$ conductance is a product of the number of channels in the $\beta$-cell membrane and the open probability of the channel at a given metabolic state dictated by channel gating properties, correlation between channel defects and disease phenotype would require thorough analysis of the impact of a mutation on both channel expression and channel gating as well as consideration of the genetic context of the mutation.
Table 2 | Neonatal Diabetes-associated $K_{\text {ATP }}$ channel trafficking mutations and response to sulfonylurea treatment.

\begin{tabular}{|c|c|c|c|}
\hline Mutation & $\begin{array}{l}\text { Surface expression } \\
\text { increased by SU }\end{array}$ & $\begin{array}{l}\text { Gating } \\
\text { property }\end{array}$ & References \\
\hline \multicolumn{4}{|l|}{ SUR1 } \\
\hline F132L & Yes & Increased $\mathrm{P}_{\mathrm{o}}$ & Pratt et al., 2009 \\
\hline V324M & N.D. & $\begin{array}{l}\text { Increased MgADP } \\
\text { sensitivity }\end{array}$ & Zhou et al., 2010 \\
\hline \multicolumn{4}{|l|}{ Kir6.2 } \\
\hline C42R & N.D. & Increased $\mathrm{P}_{0}$ & Yorifuji et al., 2005 \\
\hline Q52R & Yes & Increased $\mathrm{P}_{0}$ & $\begin{array}{l}\text { Proks et al., 2004; } \\
\text { Lin et al., 2006a }\end{array}$ \\
\hline V59G & Yes & Increased $P_{0}$ & $\begin{array}{l}\text { Proks et al., 2004; } \\
\text { Lin et al., 2006a }\end{array}$ \\
\hline V59M & Yes & Increased $P_{0}$ & $\begin{array}{l}\text { Koster et al., 2005; } \\
\text { Lin et al., 2006a }\end{array}$ \\
\hline R201C & Yes & $\begin{array}{l}\text { Decreased ATP } \\
\text { inhibition }\end{array}$ & $\begin{array}{l}\text { Proks et al., 2004; } \\
\text { Lin et al., 2006a }\end{array}$ \\
\hline $\mathrm{R} 201 \mathrm{H}$ & Yes & $\begin{array}{l}\text { Decreased ATP } \\
\text { inhibition }\end{array}$ & $\begin{array}{l}\text { Proks et al., 2004; } \\
\text { Lin et al., 2006a }\end{array}$ \\
\hline $\begin{array}{l}\text { Pro226_ } \\
\text { Pro232del }\end{array}$ & N.D. & Increased $\mathrm{P}_{\mathrm{o}}$ & Lin et al., 2013 \\
\hline I296L & Yes & Increased $\mathrm{P}_{0}$ & $\begin{array}{l}\text { Proks et al., 2005; } \\
\text { Lin et al., 2006a }\end{array}$ \\
\hline
\end{tabular}

\section{CONCLUSIONS AND PERSPECTIVES}

Pharmacological chaperones have emerged as promising therapeutic tools for treating diseases resulting from defective protein folding and/or trafficking. Demonstration that sulfonylureas and $\mathrm{CBZ}$ are effective pharmacological agents able to restore surface expression of $\mathrm{K}_{\mathrm{ATP}}$ trafficking mutants identified in congenital hyperinsulinism has direct clinical relevance. As CBZ is an FDAapproved drug, it may stand to rapidly improve current therapies for patients harboring trafficking mutations within TMD0 of SUR1. In order to spur translation of these findings into real treatment, an important next step is to demonstrate the efficacy of CBZ in $\beta$-cells isolated from CHI patients with $\mathrm{K}_{\mathrm{ATP}}$ trafficking mutations within TMD0. Also, currently only a subset of identified TMD0 trafficking mutations associated with disease has been examined for their ability to be rescued by CBZ. The therapeutic applicability of CBZ for treating $K_{\text {ATP }}$ trafficking disorders will likely expand in the future as more mutations are identified and tested. Finally, although CBZ also inhibits $\mathrm{K}_{\mathrm{ATP}}$ channel function, this inhibition is reversible and can be partially overcome by co-application of potentiators, such as diazoxide, without compromising CBZ's corrector effect. These findings represent significant improvements over pharmacological rescue using glibenclamide, but CBZ itself may only be a model demonstrating the potential that future pharmacological correctors hold for treating $\mathrm{K}_{\mathrm{ATP}}$ channel trafficking disorders.

Beyond the therapeutic implications, in vitro studies utilizing pharmacological chaperones and naturally occurring mutations in $\mathrm{K}_{\mathrm{ATP}}$ channel subunits have enhanced our understanding of structure-function relationships in terms of biogenesis and molecular assembly, as well as gating and coupling between subunits. For instance, the finding that only trafficking mutations 
within TMD0 of SUR1 are amenable to pharmacological rescue further underscores the importance of this unique domain in mediating subunit interactions with Kir6.2 and highlights a role of TMD0 in channel assembly. The fact that drug binding, at least in the case of sulfonlylureas, to L0 and TMD2 of SUR1 as well as N-terminus of Kir6.2 has functional consequences for mutations within TMD0 suggests that either these domains can physically interact or there is a mechanism for transducing structural changes in trans to TMD0. Further, the fact that some $\mathrm{K}_{\mathrm{ATP}}$ trafficking mutants rescued by reversible inhibitors (CBZ, tolbutamide) are functional upon drug washout and retain normal responses to metabolic signals and pharmacological ligands implies that these residues in TMD0 are not involved in gating or other functional aspects of the channel, but likely play important roles in the folding of this domain or may even be key residues at the interface of SUR1 and Kir6.2. At present, it is unclear whether CBZ binds directly to the channel complex during biogenesis or impacts channel expression and gating indirectly through interactions with other proteins. If CBZ does interact directly, defining the binding sites on $\mathrm{K}_{\mathrm{ATP}}$ will provide valuable information on the mechanism by which this drug modulates channel folding, assembly and gating. This knowledge is critically important for future efforts to design more effective drugs that will target the biogenesis or gating defects of disease-causing mutant $\mathrm{K}_{\mathrm{ATP}}$ channels.

\section{ACKNOWLEDGMENTS}

This work was supported by National Institutes of Health grant DK57699 and DK66485 (to Show-Ling Shyng). Gregory Martin is supported by an NIH Ruth L. Kirschstein T32 PMCB Training Grant.

\section{REFERENCES}

Aguilar-Bryan, L., and Bryan, J. (1999). Molecular biology of adenosine triphosphate-sensitive potassium channels. Endocr. Rev. 20, 101-135. doi: 10.1210/er.20.2.101

Aguilar-Bryan, L., Clement, J. P. T., Gonzalez, G., Kunjilwar, K., Babenko, A., and Bryan, J. (1998). Toward understanding the assembly and structure of KATP channels. Physiol. Rev. 78, 227-245.

Aguilar-Bryan, L., Nelson, D. A., Vu, Q. A., Humphrey, M. B., and Boyd, A. E. 3rd. (1990). Photoaffinity labeling and partial purification of the beta cell sulfonylurea receptor using a novel, biologically active glyburide analog. J. Biol. Chem. 265, 8218-8224.

Aguilar-Bryan, L., Nichols, C. G., Wechsler, S. W., Clement, J. P. T., Boyd, A. E. 3rd., Gonzalez, G., et al. (1995). Cloning of the beta cell high-affinity sulfonylurea receptor: a regulator of insulin secretion. Science 268, 423-426. doi: 10.1126/science.7716547

Alekseev, A. E., Kennedy, M. E., Navarro, B., and Terzic, A. (1997). Burst kinetics of co-expressed Kir6.2/SUR1 clones: comparison of recombinant with native ATP-sensitive K+ channel behavior. J. Membr. Biol. 159, 161-168. doi: $10.1007 / \mathrm{s} 002329900279$

Ambrosio, A. F., Soares-Da-Silva, P., Carvalho, C. M., and Carvalho, A. P. (2002). Mechanisms of action of carbamazepine and its derivatives, oxcarbazepine, BIA 2-093, and BIA 2-024. Neurochem. Res. 27, 121-130. doi: 10.1023/A:1014814924965

Antcliff, J. F., Haider, S., Proks, P., Sansom, M. S., and Ashcroft, F. M. (2005). Functional analysis of a structural model of the ATP-binding site of the KATP channel Kir6.2 subunit. EMBO J. 24, 229-239. doi: 10.1038/sj.emboj.7600487

Ashcroft, F. M. (2005). ATP-sensitive potassium channelopathies: focus on insulin secretion. J. Clin. Invest. 115, 2047-2058. doi: 10.1172/JCI25495

Ashfield, R., Gribble, F. M., Ashcroft, S. J., and Ashcroft, F. M. (1999). Identification of the high-affinity tolbutamide site on the SUR1 subunit of the K(ATP) channel. Diabetes 48, 1341-1347. doi: 10.2337/diabetes.48. 6.1341
Babenko, A. P. (2005). K(ATP) channels "vingt ans apres": ATG to PDB to Mechanism. J. Mol. Cell. Cardiol. 39, 79-98. doi: 10.1016/j.yjmcc.2004.12.004

Babenko, A. P., and Bryan, J. (2003). SUR domains that associate with and gate KATP pores define a novel gatekeeper. J. Biol. Chem. 278, 41577. doi: 10.1074/jbc.C300363200

Babenko, A. P., Gonzalez, G., and Bryan, J. (1999). Two regions of sulfonylurea receptor specify the spontaneous bursting and ATP inhibition of KATP channel isoforms. J. Biol. Chem. 274, 11587-11592. doi: 10.1074/jbc.274.17.11587

Baukrowitz, T., Schulte, U., Oliver, D., Herlitze, S., Krauter, T., Tucker, S. J., et al. (1998). PIP2 and PIP as determinants for ATP inhibition of KATP channels. Science 282, 1141-1144. doi: 10.1126/science.282.5391.1141

Branstrom, R., Leibiger, I. B., Leibiger, B., Corkey, B. E., Berggren, P. O., and Larsson, O. (1998). Long chain coenzyme A esters activate the pore-forming subunit (Kir6. 2) of the ATP-regulated potassium channel. J. Biol. Chem. 273, 31395-31400. doi: 10.1074/jbc.273.47.31395

Brown, C. R., Hong-Brown, L. Q., Biwersi, J., Verkman, A. S., and Welch, W. J. (1996). Chemical chaperones correct the mutant phenotype of the delta F508 cystic fibrosis transmembrane conductance regulator protein. Cell Stress Chaperones 1, 117-125.doi: 10.1379/1466-1268(1996)001<0117:CCCTMP>2.3.CO;2

Brown, G. R., and Foubister, A. J. (1984). Receptor binding sites of hypoglycemic sulfonylureas and related [(acylamino)alkyl]benzoic acids. J. Med. Chem. 27, 79-81. doi: $10.1021 / \mathrm{jm} 00367 \mathrm{a} 016$

Bryan, J., Vila-Carriles, W. H., Zhao, G., Babenko, A. P., and Aguilar-Bryan, L. (2004). Toward linking structure with function in ATP-sensitive K+ channels. Diabetes 53(Suppl. 3), S104-S112. doi: 10.2337/diabetes.53.suppl_3.S104

Capener, C. E., Shrivastava, I. H., Ranatunga, K. M., Forrest, L. R., Smith, G. R., and Sansom, M. S. (2000). Homology modeling and molecular dynamics simulation studies of an inward rectifier potassium channel. Biophys. J. 78, 2929-2942. doi: 10.1016/S0006-3495(00)76833-0

Carlile, G. W., Robert, R., Zhang, D., Teske, K. A., Luo, Y., Hanrahan, J. W., et al. (2007). Correctors of protein trafficking defects identified by a novel high-throughput screening assay. Chembiochem 8, 1012-1020. doi: $10.1002 /$ cbic.200700027

Cartier, E. A., Conti, L. R., Vandenberg, C. A., and Shyng, S. L. (2001). Defective trafficking and function of KATP channels caused by a sulfonylurea receptor 1 mutation associated with persistent hyperinsulinemic hypoglycemia of infancy. Proc. Natl. Acad. Sci. U.S.A. 98, 2882-2887. doi: 10.1073/pnas. 051499698

Chan, K. W., Zhang, H., and Logothetis, D. E. (2003). N-terminal transmembrane domain of the SUR controls trafficking and gating of Kir6 channel subunits. EMBO J. 22, 3833-3843. doi: 10.1093/emboj/cdg376

Chen, P. C., Bruederle, C. E., Gaisano, H. Y., and Shyng, S. L. (2011). Syntaxin 1A regulates surface expression of beta-cell ATP-sensitive potassium channels. Am. J. Physiol. Cell Physiol. 300, C506-C516. doi: 10.1152/ajpcell.00429. 2010

Chen, P. C., Kryukova, Y. N., and Shyng, S. L. (2013a). Leptin regulates KATP channel trafficking in pancreatic beta-cells by a signaling mechanism involving AMPK and PKA. J. Biol. Chem. 288, 34098-34109. doi: 10.1074/jbc.M113.516880

Chen, P. C., Olson, E. M., Zhou, Q., Kryukova, Y., Sampson, H. M., Thomas, D. Y., et al. (2013b). Carbamazepine as a novel small molecule corrector of traffickingimpaired ATP-sensitive potassium channels identified in congenital hyperinsulinism. J. Biol. Chem. 288, 20942-20954. doi: 10.1074/jbc.M113.470948

Cheng, S. H., Gregory, R. J., Marshall, J., Paul, S., Souza, D. W., White, G. A., et al. (1990). Defective intracellular transport and processing of CFTR is the molecular basis of most cystic fibrosis. Cell 63, 827-834. doi: 10.1016/00928674(90)90148-8

Clement, J. P. T., Kunjilwar, K., Gonzalez, G., Schwanstecher, M., Panten, U., Aguilar-Bryan, L., et al. (1997). Association and stoichiometry of K(ATP) channel subunits. Neuron 18, 827-838. doi: 10.1016/S0896-6273(00)80321-9

Conti, L. R., Radeke, C. M., Shyng, S. L., and Vandenberg, C. A. (2001). Transmembrane topology of the sulfonylurea receptor SUR1. J. Biol. Chem. 276, 41270-41278. doi: 10.1074/jbc.M106555200

Conti, L. R., Radeke, C. M., and Vandenberg, C. A. (2002). Membrane targeting of ATP-sensitive potassium channel. Effects of glycosylation on surface expression. J. Biol. Chem. 277, 25416-25422. doi: 10.1074/jbc.M203109200

Crane, A., and Aguilar-Bryan, L. (2004). Assembly, maturation, and turnover of K(ATP) channel subunits. J. Biol. Chem. 279, 9080-9090. doi: 10.1074/jbc.M311079200 
Cukras, C. A., Jeliazkova, I., and Nichols, C. G. (2002a). The role of NH2-terminal positive charges in the activity of inward rectifier KATP channels. J. Gen. Physiol. 120, 437-446. doi: 10.1085/jgp.20028621

Cukras, C. A., Jeliazkova, I., and Nichols, C. G. (2002b). Structural and functional determinants of conserved lipid interaction domains of inward rectifying Kir6.2 channels. J. Gen. Physiol. 119, 581-591. doi: 10.1085/jgp.20028562

Denning, G. M., Anderson, M. P., Amara, J. F., Marshall, J., Smith, A. E., and Welsh, M. J. (1992). Processing of mutant cystic fibrosis transmembrane conductance regulator is temperature-sensitive. Nature 358, 761-764. doi: 10.1038/358761a0

Detimary, P., Dejonghe, S., Ling, Z., Pipeleers, D., Schuit, F., and Henquin, J. C. (1998). The changes in adenine nucleotides measured in glucose-stimulated rodent islets occur in beta cells but not in alpha cells and are also observed in human islets. J. Biol. Chem. 273, 33905-33908. doi: 10.1074/jbc.273.51.33905

De Wet, H., Mikhailov, M. V., Fotinou, C., Dreger, M., Craig, T. J., Venien-Bryan, C., et al. (2007). Studies of the ATPase activity of the ABC protein SUR1. FEBS J. 274, 3532-3544. doi: 10.1111/j.1742-4658.2007.05879.x

Drain, P., Geng, X., and Li, L. (2004). Concerted gating mechanism underlying KATP channel inhibition by ATP. Biophys. J. 86, 2101-2112. doi: 10.1016/S00063495(04)74269-1

Drumm, M. L., Wilkinson, D. J., Smit, L. S., Worrell, R. T., Strong, T. V., Frizzell, R. A., et al. (1991). Chloride conductance expressed by delta F508 and other mutant CFTRs in Xenopus oocytes. Science 254, 1797-1799. doi: 10.1126/science. 1722350

Dunne, M. J., Yule, D. I., Gallacher, D. V., and Petersen, O. H. (1989). Cromakalim (BRL 34915) and diazoxide activate ATP-regulated potassium channels in insulin-secreting cells. Pflugers Arch. 414(Suppl. 1), S154-S155. doi: 10.1007/BF00582279

Faletra, F., Snider, K., Shyng, S. L., Bruno, I., Athanasakis, E., Gasparini, P., et al. (2013). Co-inheritance of two ABCC8 mutations causing an unresponsive congenital hyperinsulinism: clinical and functional characterization of two novel ABCC8 mutations. Gene 516, 122-125. doi: 10.1016/j.gene.2012.12.055

Fan, J. Q., Ishii, S., Asano, N., and Suzuki, Y. (1999). Accelerated transport and maturation of lysosomal alpha-galactosidase A in Fabry lymphoblasts by an enzyme inhibitor. Nat. Med. 5, 112-115. doi: 10.1038/4801

Fukuda, Y., Aguilar-Bryan, L., Vaxillaire, M., Dechaume, A., Wang, Y., Dean, M., et al. (2011). Conserved intramolecular disulfide bond is critical to trafficking and fate of ATP-binding cassette (ABC) transporters ABCB6 and sulfonylurea receptor 1 (SUR1)/ABCC8. J. Biol. Chem. 286, 8481-8492. doi: 10.1074/jbc.M110.174516

Giblin, J. P., Leaney, J. L., and Tinker, A. (1999). The molecular assembly of ATPsensitive potassium channels. Determinants on the pore forming subunit. $J$. Biol. Chem. 274, 22652-22659. doi: 10.1074/jbc.274.32.22652

Giblin, J. P., Quinn, K., and Tinker, A. (2002). The cytoplasmic C-terminus of the sulfonylurea receptor is important for KATP channel function but is not key for complex assembly or trafficking. Eur. J. Biochem. 269, 5303-5313. doi: 10.1046/j.1432-1033.2002.03249.x

Gloyn, A. L., Pearson, E. R., Antcliff, J. F., Proks, P., Bruining, G. J., Slingerland, A. S., et al. (2004). Activating mutations in the gene encoding the ATP-sensitive potassium-channel subunit Kir6.2 and permanent neonatal diabetes. N. Engl. J. Med. 350, 1838-1849. doi: 10.1056/NEJMoa032922

Gribble, F. M., and Reimann, F. (2003a). Differential selectivity of insulin secretagogues: mechanisms, clinical implications, and drug interactions. J. Diabetes Complications 17, 11-15. doi: 10.1016/S1056-8727(02)00272-6

Gribble, F. M., and Reimann, F. (2003b). Sulphonylurea action revisited: the postcloning era. Diabetologia 46, 875-891. doi: 10.1007/s00125-003-1143-3

Gribble, F. M., Tucker, S. J., and Ashcroft, F. M. (1997). The essential role of the Walker A motifs of SUR1 in K-ATP channel activation by Mg-ADP and diazoxide. EMBO J. 16, 1145-1152. doi: 10.1093/emboj/16.6.1145

Hanrahan, J. W., Sampson, H. M., and Thomas, D. Y. (2013). Novel pharmacological strategies to treat cystic fibrosis. Trends Pharmacol. Sci. 34, 119-125. doi: 10.1016/j.tips.2012.11.006

Hattersley, A. T., and Ashcroft, F. M. (2005). Activating mutations in Kir6.2 and neonatal diabetes: new clinical syndromes, new scientific insights, and new therapy. Diabetes 54, 2503-2513. doi: 10.2337/diabetes.54.9.2503

Heusser, K., Yuan, H., Neagoe, I., Tarasov, A. I., Ashcroft, F. M., and Schwappach, B. (2006). Scavenging of 14-3-3 proteins reveals their involvement in the cellsurface transport of ATP-sensitive K+ channels. J. Cell Sci. 119, 4353-4363. doi: $10.1242 /$ jcs. 03196

Hidvegi, T., Ewing, M., Hale, P., Dippold, C., Beckett, C., Kemp, C., et al. (2010). An autophagy-enhancing drug promotes degradation of mutant alphal-antitrypsin $\mathrm{Z}$ and reduces hepatic fibrosis. Science 329, 229-232. doi: $10.1126 /$ science. 1190354

Inagaki, N., Gonoi, T., Clement, J. P. T., Namba, N., Inazawa, J., Gonzalez, G., et al. (1995). Reconstitution of IKATP: an inward rectifier subunit plus the sulfonylurea receptor. Science 270, 1166-1170. doi: 10.1126/science.270.5239.1166

Inagaki, N., Gonoi, T., and Seino, S. (1997). Subunit stoichiometry of the pancreatic beta-cell ATP-sensitive K+ channel. FEBS Lett. 409, 232-236. doi: 10.1016/S0014-5793(97)00488-2

Jensen, T. J., Loo, M. A., Pind, S., Williams, D. B., Goldberg, A. L., and Riordan, J. R. (1995). Multiple proteolytic systems, including the proteasome, contribute to CFTR processing. Cell 83, 129-135. doi: 10.1016/0092-8674(95)90241-4

Koster, J. C., Remedi, M. S., Dao, C., and Nichols, C. G. (2005). ATP and sulfonylurea sensitivity of mutant ATP-sensitive $\mathrm{K}+$ channels in neonatal diabetes: implications for pharmacogenomic therapy. Diabetes 54, 2645-2654. doi: 10.2337/diabetes.54.9.2645

Koster, J. C., Sha, Q., and Nichols, C. G. (1999). Sulfonylurea and K(+)-channel opener sensitivity of K(ATP) channels. Functional coupling of Kir6.2 and SUR1 subunits. J. Gen. Physiol. 114, 203-213. doi: 10.1085/jgp.114.2.203

Kramer, W., Oekonomopulos, R., Punter, J., and Summ, H. D. (1988). Direct photoaffinity labeling of the putative sulfonylurea receptor in rat beta-cell tumor membranes by [3H] glibenclamide. FEBS Lett. 229, 355-359. doi: 10.1016/00145793(88)81155-4

Larsson, O., Deeney, J. T., Branstrom, R., Berggren, P. O., and Corkey, B. E. (1996). Activation of the ATP-sensitive $\mathrm{K}+$ channel by long chain acyl-CoA. A role in modulation of pancreatic beta-cell glucose sensitivity. J. Biol. Chem. 271, 10623-10626. doi: 10.1074/jbc.271.18.10623

Li, J. B., Huang, X., Zhang, R. S., Kim, R. Y., Yang, R., and Kurata, H. T. (2013). Decomposition of slide helix contributions to ATP-dependent inhibition of Kir6.2 channels. J. Biol. Chem. 288, 23038-23049. doi: 10.1074/jbc.M113.485789

Lilley, B. N., and Ploegh, H. L. (2004). A membrane protein required for dislocation of misfolded proteins from the ER. Nature 429, 834-840. doi: 10.1038 /nature02592

Lin, C. W., Lin, Y. W., Yan, F. F., Casey, J., Kochhar, M., Pratt, E. B., et al. (2006a) Kir6.2 mutations associated with neonatal diabetes reduce expression of ATPSensitive K+ channels: implications in disease mechanism and sulfonylurea therapy. Diabetes 55, 1738-1746. doi: 10.2337/db05-1571

Lin, Y. W., Macmullen, C., Ganguly, A., Stanley, C. A., and Shyng, S. L. (2006b). A novel KCNJ11 mutation associated with congenital hyperinsulinism reduces the intrinsic open probability of beta-cell ATP-sensitive potassium channels. J. Biol. Chem. 281, 3006-3012. doi: 10.1074/jbc.M511875200

Lin, C. W., Yan, F., Shimamura, S., Barg, S., and Shyng, S. L. (2005). Membrane phosphoinositides control insulin secretion through their effects on ATPsensitive $\mathrm{K}+$ channel activity. Diabetes 54, 2852-2858. doi: 10.2337/diabetes.54.10.2852

Lin, Y. W., Bushman, J. D., Yan, F. F., Haidar, S., Macmullen, C., Ganguly, A., et al. (2008). Destabilization of ATP-sensitive potassium channel activity by novel KCNJ11 mutations identified in congenital hyperinsulinism. J. Biol. Chem. 283, 9146-9156. doi: 10.1074/jbc.M708798200

Lin, Y. W., Li, A., Grasso, V., Battaglia, D., Crino, A., Colombo, C., et al. (2013). Functional characterization of a novel KCNJ11 in frame mutationdeletion associated with infancy-onset diabetes and a mild form of intermediate DEND: a battle between K(ATP) gain of channel activity and loss of channel expression. PLoS ONE 8:e63758. doi: 10.1371/journal.pone. 0063758

Loo, T. W., and Clarke, D. M. (1997). Correction of defective protein kinesis of human P-glycoprotein mutants by substrates and modulators. J. Biol. Chem. 272, 709-712. doi: 10.1074/jbc.272.2.709

Loo, T. W., and Clarke, D. M. (1998). Superfolding of the partially unfolded coreglycosylated intermediate of human P-glycoprotein into the mature enzyme is promoted by substrate- induced transmembrane domain interactions. J. Biol. Chem. 273, 14671-14674. doi: 10.1074/jbc.273.24.14671

Lopatin, A. N., Makhina, E. N., and Nichols, C. G. (1994). Potassium channel block by cytoplasmic polyamines as the mechanism of intrinsic rectification. Nature 372, 366-369. doi: 10.1038/372366a0

Loussouarn, G., Phillips, L. R., Masia, R., Rose, T., and Nichols, C. G. (2001). Flexibility of the Kir6.2 inward rectifier $\mathrm{K}(+)$ channel pore. Proc. Natl. Acad. Sci. U.S.A. 98, 4227-4232. doi: 10.1073/pnas.061452698

Macmullen, C. M., Zhou, Q., Snider, K. E., Tewson, P. H., Becker, S. A., Aziz, A. R., et al. (2011). Diazoxide-unresponsive congenital hyperinsulinism in children 
with dominant mutations of the beta-cell sulfonylurea receptor SUR1. Diabetes 60, 1797-1804. doi: 10.2337/db10-1631

Manley, P. W., Quast, U., Andres, H., and Bray, K. (1993). Synthesis of and radioligand binding studies with a tritiated pinacidil analogue: receptor interactions of structurally different classes of potassium channel openers and blockers. J. Med. Chem. 36, 2004-2010. doi: 10.1021/jm00066a009

Manna, P. T., Smith, A. J., Taneja, T. K., Howell, G. J., Lippiat, J. D., and Sivaprasadarao, A. (2010). Constitutive endocytic recycling and protein kinase C-mediated lysosomal degradation control K(ATP) channel surface density. J. Biol. Chem. 285, 5963-5973. doi: 10.1074/jbc.M109.066902

Markworth, E., Schwanstecher, C., and Schwanstecher, M. (2000). ATP4- mediates closure of pancreatic beta-cell ATP-sensitive potassium channels by interaction with 1 of 4 identical sites. Diabetes 49, 1413-1418. doi: 10.2337/diabetes.49.9.1413

Marthinet, E., Bloc, A., Oka, Y., Tanizawa, Y., Wehrle-Haller, B., Bancila, V., et al. (2005). Severe congenital hyperinsulinism caused by a mutation in the Kir6.2 subunit of the adenosine triphosphate-sensitive potassium channel impairing trafficking and function. J. Clin. Endocrinol. Metab. 90, 5401-5406. doi: 10.1210/jc.2005-0202

Masia, R., Enkvetchakul, D., and Nichols, C. G. (2005). Differential nucleotide regulation of KATP channels by SUR1 and SUR2A. J. Mol. Cell. Cardiol. 39, 491-501. doi: 10.1016/j.yjmcc.2005.03.009

Masia, R., and Nichols, C. G. (2008). Functional clustering of mutations in the dimer interface of the nucleotide binding folds of the sulfonylurea receptor. J. Biol. Chem. 283, 30322-30329. doi: 10.1074/jbc.M804318200

Matsuo, M., Kimura, Y., and Ueda, K. (2005). KATP channel interaction with adenine nucleotides. J. Mol. Cell. Cardiol. 38, 907-916. doi: 10.1016/j.yjmcc.2004.11.021

Mikhailov, M. V., Campbell, J. D., De Wet, H., Shimomura, K., Zadek, B., Collins, R. F., et al. (2005). 3-D structural and functional characterization of the purified KATP channel complex Kir6.2-SUR1. EMBO J. 24, 4166-4175. doi: 10.1038/sj.emboj.7600877

Moreau, C., Jacquet, H., Prost, A. L., D'hahan, N., and Vivaudou, M. (2000). The molecular basis of the specificity of action of K(ATP) channel openers. EMBO J. 19, 6644-6651. doi: 10.1093/emboj/19.24.6644

Morello, J. P., Salahpour, A., Laperriere, A., Bernier, V., Arthus, M. F., Lonergan, M., et al. (2000). Pharmacological chaperones rescue cell-surface expression and function of misfolded V2 vasopressin receptor mutants. J. Clin. Invest. 105, 887-895. doi: 10.1172/JCI8688

Muzyamba, M., Farzaneh, T., Behe, P., Thomas, A., Christesen, H. B., Brusgaard, K., et al. (2007). Complex ABCC8 DNA variations in congenital hyperinsulinism: lessons from functional studies. Clin. Endocrinol. (Oxf). 67, 115-124. doi: 10.1111/j.1365-2265.2007.02847.x

Nestorowicz, A., Glaser, B., Wilson, B. A., Shyng, S. L., Nichols, C. G., Stanley, C. A., et al. (1998). Genetic heterogeneity in familial hyperinsulinism. Hum. Mol. Genet. 7, 1119-1128. doi: 10.1093/hmg/7.7.1119

Nestorowicz, A., Inagaki, N., Gonoi, T., Schoor, K. P., Wilson, B. A., Glaser, B., et al. (1997). A nonsense mutation in the inward rectifier potassium channel gene, Kir6.2, is associated with familial hyperinsulinism. Diabetes 46, 1743-1748. doi: 10.2337/diab.46.11.1743

Nichols, C. G. (2006). KATP channels as molecular sensors of cellular metabolism. Nature 440, 470-476. doi: 10.1038/nature04711

Nichols, C. G., and Lopatin, A. N. (1997). Inward rectifier potassium channels. Annu. Rev. Physiol. 59, 171-191. doi: 10.1146/annurev.physiol.59.1.171

Nichols, C. G., Makhina, E. N., Pearson, W. L., Sha, Q., and Lopatin, A. N. (1996a). Inward rectification and implications for cardiac excitability. Circ. Res. 78, 1-7. doi: 10.1161/01.RES.78.1.1

Nichols, C. G., Shyng, S. L., Nestorowicz, A., Glaser, B., Clement, J. P. T., Gonzalez, G., et al. (1996b). Adenosine diphosphate as an intracellular regulator of insulin secretion. Science 272, 1785-1787. doi: 10.1126/science.272.5269.1785

Nilsson, T., Schultz, V., Berggren, P. O., Corkey, B. E., and Tornheim, K. (1996). Temporal patterns of changes in ATP/ADP ratio, glucose 6-phosphate and cytoplasmic free $\mathrm{Ca} 2+$ in glucose-stimulated pancreatic beta-cells. Biochem. J. 314(pt 1), 91-94.

Noma, A. (1983). ATP-regulated $\mathrm{K}+$ channels in cardiac muscle. Nature 305, 147-148. doi: 10.1038/305147a0

Ortiz, D., Gossack, L., Quast, U., and Bryan, J. (2013). Reinterpreting the action of ATP analogs on K(ATP) channels. J. Biol. Chem. 288, 18894-18902. doi: 10.1074/jbc.M113.476887
Ortiz, D., Voyvodic, P., Gossack, L., Quast, U., and Bryan, J. (2012). Two neonatal diabetes mutations on transmembrane helix 15 of SUR1 increase affinity for ATP and ADP at nucleotide binding domain 2. J. Biol. Chem. 287, 17985-17995. doi: 10.1074/jbc.M112.349019

Partridge, C. J., Beech, D. J., and Sivaprasadarao, A. (2001). Identification and pharmacological correction of a membrane trafficking defect associated with a mutation in the sulfonylurea receptor causing familial hyperinsulinism. J. Biol. Chem. 276, 35947-35952. doi: 10.1074/jbc.M104762200

Pedemonte, N., Lukacs, G. L., Du, K., Caci, E., Zegarra-Moran, O., Galietta, L. J., et al. (2005). Small-molecule correctors of defective DeltaF508-CFTR cellular processing identified by high-throughput screening. J. Clin. Invest. 115, 2564-2571. doi: 10.1172/JCI24898

Powell, P. D., Bellanne-Chantelot, C., Flanagan, S. E., Ellard, S., Rooman, R., Hussain, K., et al. (2011). In vitro recovery of ATP-sensitive potassium channels in beta-cells from patients with congenital hyperinsulinism of infancy. Diabetes 60, 1223-1228. doi: 10.2337/db10-1443

Powers, E. T., Morimoto, R. I., Dillin, A., Kelly, J. W., and Balch, W. E. (2009). Biological and chemical approaches to diseases of proteostasis deficiency. Annu. Rev. Biochem. 78, 959-991. doi: 10.1146/annurev.biochem.052308.114844

Pratt, E. B., Tewson, P., Bruederle, C. E., Skach, W. R., and Shyng, S. L. (2011). N-terminal transmembrane domain of SUR1 controls gating of Kir6.2 by modulating channel sensitivity to PIP2. J. Gen. Physiol. 137, 299-314. doi: 10.1085/jgp.201010557

Pratt, E. B., Yan, F. F., Gay, J. W., Stanley, C. A., and Shyng, S. L. (2009). Sulfonylurea receptor 1 mutations that cause opposite insulin secretion defects with chemical chaperone exposure. J. Biol. Chem. 284, 7951-7959. doi: 10.1074/jbc.M807012200

Proks, P., Antcliff, J. F., Lippiat, J., Gloyn, A. L., Hattersley, A. T., and Ashcroft, F. M. (2004). Molecular basis of Kir6.2 mutations associated with neonatal diabetes or neonatal diabetes plus neurological features. Proc. Natl. Acad. Sci. U.S.A. 101, 17539-17544. doi: 10.1073/pnas.0404756101

Proks, P., Arnold, A. L., Bruining, J., Girard, C., Flanagan, S. E., Larkin, B., et al. (2006). A heterozygous activating mutation in the sulphonylurea receptor SUR1 (ABCC8) causes neonatal diabetes. Hum. Mol. Genet. 15, 1793-1800. doi: $10.1093 / \mathrm{hmg} / \mathrm{ddl} 101$

Proks, P., Girard, C., Haider, S., Gloyn, A. L., Hattersley, A. T., Sansom, M. S., et al. (2005). A gating mutation at the internal mouth of the Kir6.2 pore is associated with DEND syndrome. EMBO Rep. 6, 470-475. doi: 10.1038/sj.embor. 7400393

Quast, U., Stephan, D., Bieger, S., and Russ, U. (2004). The impact of ATPsensitive $\mathrm{K}+$ channel subtype selectivity of insulin secretagogues for the coronary vasculature and the myocardium. Diabetes 53(Suppl. 3), S156-S164. doi: 10.2337/diabetes.53.suppl_3.S156

Reimann, F., Tucker, S. J., Proks, P., and Ashcroft, F. M. (1999). Involvement of the n-terminus of Kir6.2 in coupling to the sulphonylurea receptor. J. Physiol. 518, 325-336. doi: 10.1111/j.1469-7793.1999.0325p.x

Riedel, M. J., and Light, P. E. (2005). Saturated and cis/trans unsaturated acyl CoA esters differentially regulate wild-type and polymorphic beta-cell ATP-sensitive K+ channels. Diabetes 54, 2070-2079. doi: 10.2337/diabetes.54.7.2070

Riordan, J. R., Rommens, J. M., Kerem, B., Alon, N., Rozmahel, R., Grzelczak, Z., et al. (1989). Identification of the cystic fibrosis gene: cloning and characterization of complementary DNA. Science 245, 1066-1073. doi: 10.1126/science. 2475911

Rowe, S. M., and Verkman, A. S. (2013). Cystic fibrosis transmembrane regulator correctors and potentiators. Cold Spring Harb. Perspect. Med. 3:a009761. doi: 10.1101/cshperspect.a009761

Sampson, H. M., Lam, H., Chen, P. C., Zhang, D., Mottillo, C., Mirza, M., et al. (2013). Compounds that correct F508del-CFTR trafficking can also correct other protein trafficking diseases: an in vitro study using cell lines. Orphanet J. Rare Dis. 8, 11. doi: 10.1186/1750-1172-8-11

Sarkar, S., Perlstein, E. O., Imarisio, S., Pineau, S., Cordenier, A., Maglathlin, R. L., et al. (2007). Small molecules enhance autophagy and reduce toxicity in Huntington's disease models. Nat. Chem. Biol. 3, 331-338. doi: 10.1038/nchembio883

Schulze, D., Rapedius, M., Krauter, T., and Baukrowitz, T. (2003). LC-CoA esters and PIPs modulate ATP inhibition of KATP channels by the same mechanism. J. Physiol. 552, 357-367. doi: 10.1113/jphysiol.2003.047035

Schwanstecher, M., Loser, S., Chudziak, F., Bachmann, C., and Panten, U. (1994). Photoaffinity labeling of the cerebral sulfonylurea receptor using a novel 
radioiodinated azidoglibenclamide analogue. J. Neurochem. 63, 698-708. doi: 10.1046/j.1471-4159.1994.63020698.x

Schwappach, B., Zerangue, N., Jan, Y. N., and Jan, L. Y. (2000). Molecular basis for K(ATP) assembly: transmembrane interactions mediate association of a K+ channel with an ABC transporter. Neuron 26, 155-167. doi: 10.1016/S08966273(00)81146-0

Schwartz, T. B., and Meinert, C. L. (2004). The UGDP controversy: thirty-four years of contentious ambiguity laid to rest. Perspect. Biol. Med. 47, 564-574. doi: $10.1353 / \mathrm{pbm} .2004 .0071$

Sharma, N., Crane, A., Clement, J. P. T., Gonzalez, G., Babenko, A. P., Bryan, J., et al. (1999). The C terminus of SUR1 is required for trafficking of KATP channels. J. Biol. Chem. 274, 20628-20632. doi: 10.1074/jbc.274.29.20628

Shyng, S. L., Cukras, C. A., Harwood, J., and Nichols, C. G. (2000). Structural determinants of PIP(2) regulation of inward rectifier K(ATP) channels. J. Gen. Physiol. 116, 599-608. doi: 10.1085/jgp.116.5.599

Shyng, S. L., Ferrigni, T., Shepard, J. B., Nestorowicz, A., Glaser, B., Permutt, M. A., et al. (1998). Functional analyses of novel mutations in the sulfonylurea receptor 1 associated with persistent hyperinsulinemic hypoglycemia of infancy. Diabetes 47, 1145-1151. doi: 10.2337/diabetes.47.7.1145

Shyng, S., and Nichols, C. G. (1997). Octameric stoichiometry of the KATP channel complex. J. Gen. Physiol. 110, 655-664. doi: 10.1085/jgp.110.6.655

Shyng, S. L., and Nichols, C. G. (1998). Membrane phospholipid control of nucleotide sensitivity of KATP channels. Science 282, 1138-1141. doi: 10.1126/science.282.5391.1138

Snider, K. E., Becker, S., Boyajian, L., Shyng, S. L., Macmullen, C., Hughes, N., et al. (2013). Genotype and phenotype correlations in 417 children with congenital hyperinsulinism. J. Clin. Endocrinol. Metab. 98, E355-E363. doi: 10.1210/jc.2012-2169

Stanley, C. A. (1997). Hyperinsulinism in infants and children. Pediatr. Clin. North Am. 44, 363-374. doi: 10.1016/S0031-3955(05)70481-8

Taneja, T. K., Mankouri, J., Karnik, R., Kannan, S., Smith, A. J., Munsey, T., et al. (2009). Sar1-GTPase-dependent ER exit of KATP channels revealed by a mutation causing congenital hyperinsulinism. Hum. Mol. Genet. 18, 2400-2413. doi: $10.1093 / \mathrm{hmg} / \mathrm{ddp} 179$

Tarasov, A., Dusonchet, J., and Ashcroft, F. (2004). Metabolic regulation of the pancreatic beta-cell ATP-sensitive K+ channel: a pas de deux. Diabetes 53(Suppl. 3), S113-S122. doi: 10.2337/diabetes.53.suppl_3.S113

Taschenberger, G., Mougey, A., Shen, S., Lester, L. B., Lafranchi, S., and Shyng, S. L. (2002). Identification of a familial hyperinsulinism-causing mutation in the sulfonylurea receptor 1 that prevents normal trafficking and function of KATP channels. J. Biol. Chem. 277, 17139-17146. doi: 10.1074/jbc.M200363200

Tornovsky, S., Crane, A., Cosgrove, K. E., Hussain, K., Lavie, J., Heyman, M., et al. (2004). Hyperinsulinism of infancy: novel ABCC8 and KCNJ11 mutations and evidence for additional locus heterogeneity. J. Clin. Endocrinol. Metab. 89, 6224-6234. doi: 10.1210/jc.2004-1233

Tucker, S. J., Gribble, F. M., Zhao, C., Trapp, S., and Ashcroft, F. M. (1997). Truncation of Kir6.2 produces ATP-sensitive $\mathrm{K}+$ channels in the absence of the sulphonylurea receptor. Nature 387, 179-183. doi: 10.1038/387179a0

Tusnady, G. E., Bakos, E., Varadi, A., and Sarkadi, B. (1997). Membrane topology distinguishes a subfamily of the ATP-binding cassette (ABC) transporters. FEBS Lett. 402, 1-3. doi: 10.1016/S0014-5793(96)01478-0

Vila-Carriles, W. H., Zhao, G., and Bryan, J. (2007). Defining a binding pocket for sulfonylureas in ATP-sensitive potassium channels. FASEB J. 21, 18-25. doi: 10.1096/fi.06-6730hyp

Wang, F., Olson, E. M., and Shyng, S. L. (2012). Role of Derlin-1 protein in proteostasis regulation of ATP-sensitive potassium channels. J. Biol. Chem. 287, 10482-10493. doi: 10.1074/jbc.M111.312223

Ward, C. L., and Kopito, R. R. (1994). Intracellular turnover of cystic fibrosis transmembrane conductance regulator. Inefficient processing and rapid degradation of wild-type and mutant proteins. J. Biol. Chem. 269, 25710-25718.

Ward, C. L., Omura, S., and Kopito, R. R. (1995). Degradation of CFTR by the ubiquitin-proteasome pathway. Cell 83, 121-127. doi: 10.1016/00928674(95)90240-6

Yan, F., Lin, C. W., Weisiger, E., Cartier, E. A., Taschenberger, G., and Shyng, S. L. (2004). Sulfonylureas correct trafficking defects of ATP-sensitive potassium channels caused by mutations in the sulfonylurea receptor. J. Biol. Chem. 279, 11096-11105. doi: 10.1074/jbc.M312810200

Yan, F. F., Casey, J., and Shyng, S. L. (2006). Sulfonylureas correct trafficking defects of disease-causing ATP-sensitive potassium channels by binding to the channel complex. J. Biol. Chem. 281, 33403-33413. doi: 10.1074/jbc.M6051 95200

Yan, F. F., Lin, C. W., Cartier, E. A., and Shyng, S. L. (2005). Role of ubiquitinproteasome degradation pathway in biogenesis efficiency of $\{$ beta $\}$-cell ATPsensitive potassium channels. Am. J. Physiol. Cell Physiol. 289, C1351-C1359. doi: 10.1152/ajpcell.00240.2005

Yan, F. F., Lin, Y. W., Macmullen, C., Ganguly, A., Stanley, C. A., and Shyng, S. L. (2007). Congenital hyperinsulinism associated ABCC8 mutations that cause defective trafficking of ATP-sensitive $\mathrm{K}+$ channels: identification and rescue. Diabetes 56, 2339-2348. doi: 10.2337/db07-0150

Yan, F. F., Pratt, E. B., Chen, P. C., Wang, F., Skach, W. R., David, L. L., et al. (2010). Role of Hsp90 in biogenesis of the beta-cell ATP-sensitive potassium channel complex. Mol. Biol. Cell 21, 1945-1954. doi: 10.1091/mbc.E10-02-0116

Yang, K., Fang, K., Fromondi, L., and Chan, K. W. (2005). Low temperature completely rescues the function of two misfolded K ATP channel disease-mutants. FEBS Lett. 579, 4113-4118. doi: 10.1016/j.febslet.2005.06.039

Yang, S. N., Wenna, N. D., Yu, J., Yang, G., Qiu, H., Yu, L., et al. (2007). Glucose recruits K(ATP) channels via non-insulin-containing dense-core granules. Cell Metab. 6, 217-228. doi: 10.1016/j.cmet.2007.08.002

Ye, Y., Shibata, Y., Yun, C., Ron, D., and Rapoport, T. A. (2004). A membrane protein complex mediates retro-translocation from the ER lumen into the cytosol. Nature 429, 841-847. doi: 10.1038/nature02656

Yorifuji, T., Nagashima, K., Kurokawa, K., Kawai, M., Oishi, M., Akazawa, Y., et al. (2005). The C42R mutation in the Kir6.2 (KCNJ11) gene as a cause of transient neonatal diabetes, childhood diabetes, or later-onset, apparently type 2 diabetes mellitus. J. Clin. Endocrinol. Metab. 90, 3174-3178. doi: 10.1210/jc.2005-0096

Yuan, H., Michelsen, K., and Schwappach, B. (2003). 14-3-3 dimers probe the assembly status of multimeric membrane proteins. Curr. Biol. 13, 638-646. doi: 10.1016/S0960-9822(03)00208-2

Zerangue, N., Schwappach, B., Jan, Y. N., and Jan, L. Y. (1999). A new ER trafficking signal regulates the subunit stoichiometry of plasma membrane K(ATP) channels. Neuron 22, 537-548. doi: 10.1016/S0896-6273(00)80708-4

Zhou, Q., Garin, I., Castano, L., Argente, J., Munoz-Calvo, M. T., Perez De Nanclares, G., et al. (2010). Neonatal diabetes caused by mutations in sulfonylurea receptor 1: interplay between expression and $\mathrm{Mg}$-nucleotide gating defects of ATP-sensitive potassium channels. J. Clin. Endocrinol. Metab. 95, E473-E478. doi: 10.1210/jc.2010-1231

Zhou, Q., Pratt, E. B., and Shyng, S. L. (2013). Engineered Kir6.2 mutations that correct the trafficking defect of KATP channels caused by specific SUR1 mutations. Channels (Austin) 7, 313-317. doi: 10.4161/chan. 25003

Zhou, Z., Gong, Q., and January, C. T. (1999). Correction of defective protein trafficking of a mutant HERG potassium channel in human long QT syndrome Pharmacological and temperature effects. J. Biol. Chem. 274, 31123-31126. doi: $10.1074 /$ jbc.274.44.31123

Zingman, L. V., Alekseev, A. E., Bienengraeber, M., Hodgson, D., Karger, A. B., Dzeja, P. P., et al. (2001). Signaling in channel/enzyme multimers: ATPase transitions in SUR module gate ATP-sensitive K+ conductance. Neuron 31, 233-245. doi: 10.1016/S0896-6273(01)00356-7

Conflict of Interest Statement: The authors declare that the research was conducted in the absence of any commercial or financial relationships that could be construed as a potential conflict of interest.

Received: 01 October 2013; accepted: 09 December 2013; published online: 24 December 2013.

Citation: Martin GM, Chen P-C, Devaraneni P and Shyng S-L (2013) Pharmacological rescue of trafficking-impaired ATP-sensitive potassium channels. Front. Physiol. 4:386. doi: 10.3389/fphys.2013.00386

This article was submitted to Membrane Physiology and Membrane Biophysics, a section of the journal Frontiers in Physiology.

Copyright $\odot 2013$ Martin, Chen, Devaraneni and Shyng. This is an open-access article distributed under the terms of the Creative Commons Attribution License (CC BY). The use, distribution or reproduction in other forums is permitted, provided the original author(s) or licensor are credited and that the original publication in this journal is cited, in accordance with accepted academic practice. No use, distribution or reproduction is permitted which does not comply with these terms. 